OPEN ACCESS

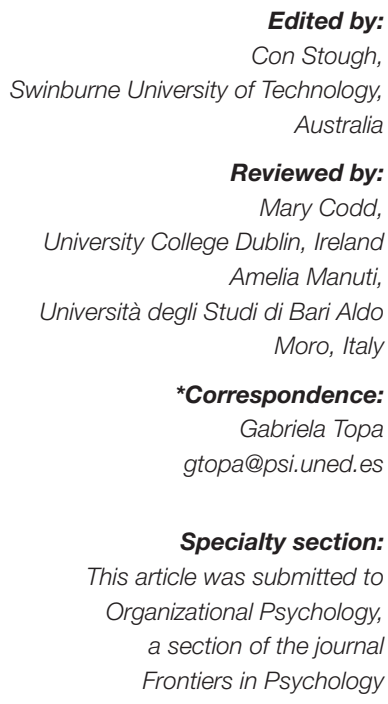

Received: 02 September 2017 Accepted: 28 November 2017 Published: 04 January 2018

Citation:

Topa G, Depolo M and Alcover C-M (2018) Early Retirement: A Meta-Analysis of Its Antecedent and Subsequent Correlates. Front. Psychol. 8:2157. doi: 10.3389/fpsyg.2017.02157

\section{Early Retirement: A Meta-Analysis of Its Antecedent and Subsequent Correlates}

\author{
Gabriela Topa ${ }^{1 *}$, Marco Depolo $^{2}$ and Carlos-Maria Alcover ${ }^{3}$ \\ ${ }^{1}$ Social and Organizational Psychology, Universidad Nacional de Educación a Distancia, Madrid, Spain, ${ }^{2}$ Psychology, \\ Università di Bologna, Bologna, Italy, ${ }^{3}$ Medicine and Surgery, Psychology, Preventive Medicine and Public Health, \\ Immunology and Medical Microbiology, Nursing, and Stomatology, Universidad Rey Juan Carlos, Madrid, Spain
}

Early or voluntary retirement (ER) can be defined as the full exit from an organizational job or career path of long duration, decided by individuals of a certain age at the mid or late career before mandatory retirement age, with the aim of reducing their attachment to work and closing a process of gradual psychological disengagement from working life. Given the swinging movements that characterize employment policies, the potential effects of ER-both for individuals and society - are still controversial. This meta-analysis examined the relationships between ER and its antecedent and subsequent correlates. Our review of the literature was generated with 151 empirical studies, containing a total number of 706,937 participants, with a wide range of sample sizes (from $N=27$ to $N$ $=127,384$ participants) and 380 independent effect sizes (ESs), which included 171 independent samples. A negligible ES value for antecedent correlates of early retirement (family pull, job stress, job satisfaction, and income) was obtained (which ranged from $r=-0.13$ to 0.19 ), while a fair ES was obtained for workplace timing for retirement, organizational pressures, financial security, and poor physical and mental health, (ranging from $r=0.28$ to 0.25). Regarding ER subsequent correlates, poor ESs were obtained, ranging from $r=0.08$ to 0.18 for the relationships with subsequent correlates, and fair ESs only for social engagement $(r=-0.25)$. Examination of the potential moderator variables has been conducted. Only a reduced percentage of variability of primary studies has been explained by moderators. Although potential moderator factors were examined, there are several unknown or not measurable factors which contribute to ER and about which there are very little data available. The discussion is aimed to offer theoretical and empirical implications suggestion in order to improve employee's well-being.

Keywords: retirement, early retirement, meta-analysis, voluntary retirement, aging

\section{INTRODUCTION}

Most developed and developing countries are experiencing demographic changes characterized both by decrease in fertility and increase in longevity. Population aging is a global phenomenon in Europe, North America, and the Asia-Pacific Region, and is often accompanied by relatively low employment rates for people aged 55 - 64 years, ranging from $73.6 \%$ in Japan, $65.0 \%$ in G7 countries, $64.1 \%$ in USA, and $59.1 \%$ in EU 28 to $53.4 \%$ in Italy and, for people 65 years and 
over, ranging from $31.5 \%$ in Korea, $19.3 \%$ in USA, $14.9 \%$ in G7 countries, and $5.7 \%$ in EU 28 to 2.0 in Spain (OECD, 2017, data from 2016). The context of high unemployment, industrial restructuring, and negative stereotypes of aged workers have contributed, especially in the last two decades of the twentieth century, to the institutionalization of early retirement (hereafter, ER) as a specific employment policy to make room for younger employees (Von Nordheim, 2004; Kim, 2009; Engelhardt, 2012). However, empirical data do not support the hypothesis that employment of the young and old are interchangeable, and suggest that encouraging later retirement will have no adverse effect on youth employment (Kalwij et al., 2010). Moreover, the welfare states have financially encouraged early withdrawal before age 60, and ER has been considered an individual right or a desirable new social status that guarantees high incomes. For decades, ER has been popular in European countries and was seen as a much appreciated social claim that increases personal satisfaction and well-being, particularly among workers who perceive poor health or who suffer from work-related health problems (Börsch-Supan and Schuth, 2014).

As a consequence, ER affected millions of workers by the end of the year 2000. With the arrival of the financial crisis and the economic downturn in 2008, the pension reform debate gained new force, and developed countries increased their pressure to reduce ER schemes, along with policies to improve the employability of aged workers. The generalized shift from "proretirement" to "pro-work" (Wang and Shultz, 2010) detected in the last decade was driven by a confluence of the needs of governments, employers, and of the older persons themselves (Komp et al., 2010). Increasing the statutory retirement age to stimulate older people to continue working, make ER financially unattractive, and make greater efforts to retain older workers in organizations are unavoidable challenges both for governments and firms (Truxillo and Fraccaroli, 2013; Bal et al., 2015). Given these swinging movements that characterize employment policies, the potential effects of ER-both for individuals and society-are still controversial (Feldman, 2003, 2013; Henkens and van Dalen, 2003; Cleveland and Lim, 2007).

\section{DEFINING ER}

ER can be defined as the full exit from an organizational job or career path of long duration, decided by individuals of a certain age at the mid or late career before mandatory retirement age, with the aim of reducing their attachment to work and closing a process of gradual psychological disengagement from working life (Beehr, 1986; Feldman, 1994; Schalk and Desmette, 2015). Previous research defined ER according to three objective criteria: age, years of service, and eligibility. But, as recent reviews of literature stated, "these objective criteria still play a major role in understanding ER decisions, but exclusive reliance on these criteria may no longer be warranted" (Feldman, 2013, p. 281). According to this recommendation, it seems necessary to take into account subjective definitions of ER, typically emerging as older workers' perceptions and attitudes about whether it is time to retire. First, normative age for retirement is the result of comparison with others in the same occupation or organization. Second, individuals view themselves as retirees, especially if they have maintained psychological distance from their work. Third, later career and life stages trigger identification with non-work roles, which in turn should drive ER decisions. Summing up, the social significance of ER has changed in the last decades and, as a consequence, both objective and subjective definitions of ER must be taken into account (Feldman, 2013; Fisher et al., 2016).

Since the pioneer works highlighted the more relevant factors of ER (Beehr, 1986; Hanisch and Hulin, 1991; Ekerdt and De Viney, 1993; Feldman, 1994; Taylor and Shore, 1995; Shultz et al., 1998; Szinovacz, 2003), a great amount of empirical studies has been published (Keith, 1985; Monahan, 1985; Hayward, 1986; Bell et al., 1989; Knesek, 1989; Swan et al., 1991; Härkäpää, 1992; Hardy and Quadagno, 1995; Cunningham, 1996; Eastman, 1996; Gowan, 1998; Edén et al., 1999; Hardy and Hazelrigg, 1999; Kerkhofs et al., 1999; Börsch-Supan, 2000; Kim and Feldman, 2000; Suh, 2000; Bahman, 2001; Rojanawon, 2001; Kim and Moen, 2002; Austrom et al., 2003; Davis, 2003; Elovainio et al., 2003; Kim, 2003; Martínez et al., 2003; Mein et al., 2003; Pauwels, 2003; Szinovacz, 2003, 2013; Tunceli, 2003; Cardano et al., 2004; Husemoen et al., 2004; Karpansalo et al., 2004; Simbula et al., 2004; Szinovacz and Davey, 2004; Blekesaune and Solem, 2005; Buxton et al., 2005; De Judicibus and McCabe, 2005; Hansez et al., 2005; Kiessling and Henriksson, 2005; Rasmussen and Andersen, 2005; Seitsamo, 2005; Taskila-Åbrandt et al., 2005; Tsai et al., 2005; Tuohy et al., 2005; Butterworth et al., 2006; Enthoven et al., 2006; Graves, 2006; Hartig and Fransson, 2006; Rennemark and Berggren, 2006; Vaillant et al., 2006; Bronchetti, 2007; Desmarez et al., 2007; Harkonmäki, 2007; Harkonmäki et al., 2007, 2009; Schuring et al., 2007; Tian, 2007; Aspnes, 2008; Boumans et al., 2008; Carlsen et al., 2008; Desmette and Gaillard, 2008; Schils, 2008; Schnabel et al., 2008; Sharma et al., 2008; Taylor et al., 2008; Brougham and Walsh, 2009; Herrbach et al., 2009; Ilchuk, 2009; Johnston and Lee, 2009; Warren, 2009; Westerlund et al., 2009; Euwals et al., 2010; Pfleger et al., 2010; Pit et al., 2010; Roberts et al., 2010; Shim and Amick, 2010; von Bonsdorff et al., 2010a; Chang and Yen, 2011; Damkjæ et al., 2011; Damman et al., 2011, 2015; Garcia, 2011; Green, 2011; Korkeila et al., 2011; Markkula et al., 2011; Sargent-Cox et al., 2011; Schneider et al., 2011; Schofield et al., 2011, 2013; Smith et al., 2011; Uggerby et al., 2011; Wuebbeke, 2011; Griffin et al., 2012; Helvik et al., 2012; Lahelma et al., 2012; Olesen et al., 2012; Paradise et al., 2012; Böttcher et al., 2013a,b; Neuner et al., 2013; Newman et al., 2013; Ranzi et al., 2013; Segel-Karpas et al., 2013; Wedegaertner et al., 2013; Dewa et al., 2014; De Wind et al., 2014; Horner, 2014; Kuhlman et al., 2014; Laires and Gouveia, 2014; Lindbohm et al., 2014; Mosca and Barrett, 2014; Osler et al., 2014; Singer et al., 2014; Van Droogenbroeck and Spruyt, 2014; Dal Bianco et al., 2015; De Wind and van der Beek, 2015; Janković et al., 2015; Lawless et al., 2015; Morois et al., 2015; Plouvier et al., 2015; Robroek et al., 2015; Ahomäki et al., 2016; Carr et al., 2016; Frilander et al., 2016; Hagger-Johnson et al., 2016; Ihle et al., 2016; Jensen et al., 2016; Laires et al., 2016; Myhr et al., 2016; Nilsson et al., 2016; Thorsen et al., 2016; Whitney et al., 2016). Despite this, only a small number of quantitative reviews have been conducted, and the quantitative reviews on 
ER only included 9 longitudinal studies and they focused on health and work factors (van den Berg et al., 2010), whereas 29 longitudinal studies focused on the relationship between health measures (self-perceived poor health, mental health problems, and chronic disease) and exit from paid employment (van Rijn et al., 2014). Another study explored the association between overweight, obesity, and lack of physical activity and exit from paid employment through disability pension, unemployment, and ER (Robroek et al., 2013). This relative scarcity of metaanalyses on retirement or ER, compared to other research fields, is probably due to the difficulty for retirement researchers to recover enough statistical information from published studies to conduct meta-analytic reviews. Due to the multidisciplinary nature of retirement research and because not every discipline requires researchers to provide these basic statistics in their papers, there are barriers to summarize and systematically review previous findings (Wang, 2013). Therefore, due to its importance in people's lives and for political decisions, conclusions based on meta-analytical findings would be beneficial to determine the links between the antecedent and subsequent correlates of ER.

In this study, meta-analytic techniques are used to summarize an increasing amount of empirical studies in order to provide a solid comprehension of the antecedent and subsequent correlates of ER and to suggest potential avenues for future research. Thus, this meta-analysis has been guided by two research questions. First, what are the main antecedent and subsequent correlates of ER? Second, what methodological and contextual factors would act as potential moderators of the relationship between ER and its antecedent and subsequent correlates? In order to answer these questions, (a) we carried out a meta-analysis of empirical studies on antecedent and subsequent correlates of ER; and (b) we explored potential moderators through analogous ANOVA and weighted regression analysis (random effects model).

\section{ANTECEDENT CORRELATES OF ER}

Whereas systematic reviews on retirement- related topics have increased during the last years, only two have been applied to the specific topic of ER. In the first, Feldman (2013) used a general model, the person-environment fit (Edwards et al., 2006), to summarize previous evidence. The person-environment fit theory states that, in order to increase their well-being, individuals try to match their characteristics to those of the environment, considered as their organizations' and groups' requirements and practices. Hence, individuals' congruence with their work environments leads them to remain longer in the job and to rate this environment as more satisfying. When person-environment fit deteriorates, individuals begin seriously considering alternatives, such as ER. As Feldman (2013) stated, fit has been conceptualized as a function of environmental levels such as occupation, organization, job, and group (Kristof-Brown et al., 2002; Vogel and Feldman, 2009).

In the second and more recent review, Fisher et al. (2016) integrated previous studies and proposed a specific model to understand the timing of retirement, including antecedent and subsequent correlates grouped in terms of family, work, and individual factors. Based on the life course perspective of retirement (Elder and Johnson, 2001), the model includes a multidisciplinary approach and emphasizes the role of interdependent life spheres (family, work, and community), as well as human agency. This personal power to define and pursue one's goals interacts with the individual constraints under which retirement occurs, such as finances and health. The present review of the antecedent correlates of ER will be conducted from Fisher, Chaffee, and Sonnega' s model, depicted in Figure 1.

\section{FAMILY-LEVEL ANTECEDENT CORRELATES}

Due to the fact that retirement typically shows an overlap of work and non-work spheres (Wang, 2007); we consider family influences that would attract older workers to ER. First, spouses who have a close relationship would be prone to retire early because they want to spend more time together. Furthermore, a spouse's illness could promote ER for caregiving. This various familial influences should be labeled as family pull. From a model based on the theory of planned behavior, van Dam et al. (2009) found that perceived spousal pressure for ER was the strongest predictor. The results obtained by Henkens (1999) suggest that ER of one of the spouses is the result of influence processes within the household, and that ER can be considered, to some extent, a household decision. But at this level, discrepancies have been found, such as those of Friis et al. (2007) and of Kim and Feldman (1998), which showed that participants with a retired or unemployed spouse had higher probabilities of ER, whereas Henkens and Tazelaar (1997) reported only insignificant relationships between having a retired partner and ER $(r=$ 0.06). Other results (Kubicek et al., 2010) show that when people (men or women, although it is probably more frequent in men) experience a high level of stress in family life, they may perceive work as a "refuge" to escape from family pressures, so they will avoid ER and postpone the decision to retire as much as possible. Thus, we expect that family pull will be positively related to ER.

\section{WORK-RELATED AND PERSON-JOB ANTECEDENT CORRELATES}

The firms' policies exert both a direct influence on ER decision, through ER incentives to encourage leaving the job, and an indirect influence through organizational downsizing or pressures toward displacement. On the one hand, there are economic incentives for ER offered by the firms, which are favorable for older workers. On the other, factors such as unsatisfied needs for continued professional training for older employees, managers' negative conceptions of aged workers, and unattractive jobs in terms of task or environmental demands should be considered organizational pressures that precipitate ER. However, empirical studies have provided mixed evidence about these relationships. For instance, Henkens and Tazelaar (1997) showed that organizational restructuring had a low relationship with ER ( $r=0.08)$, whereas Fernández Muñoz et al., 2010) found a higher correlation among organizational pressures 


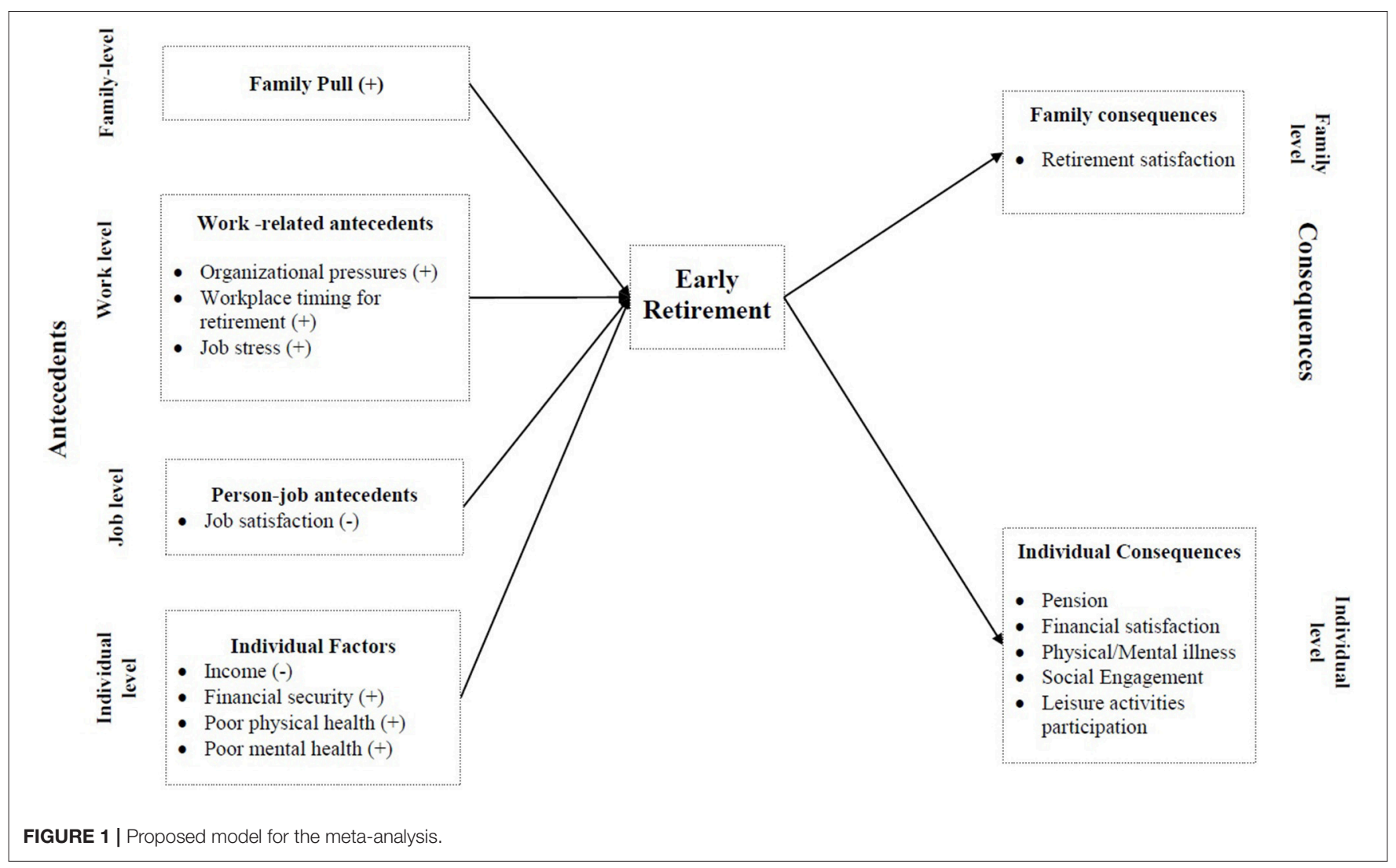

and ER acceptance $(r=0.34)$, and Alcover et al. (2012) found that organizational pressures was the most important factor for leaving work early. We expect that organizational pressures will be positively related to ER.

Besides being a personal decision, ER is affected by workplace culture, such as older workers' considering the normative time to retire from their occupations. Workplace timing for retirement refers to the assessment of how uncommon it is for someone their age to continue working (Feldman, 2013). These evaluations, called "social timing for retirement" (van Solinge, 2006), "subjective norm" (van Solinge and Henkens, 2007), or "social preferences for retirement" (van Dam et al., 2010), predispose people to retire early by facilitating the view of retirement as a normative event. Despite this theoretical consensus, research findings show discrepancies, ranging from $r=0.12$ between retirement acceptance in the workplace and ER (Whipple, 2001) and $r=0.41$ between the social norm in the workplace and ER (van Dam et al., 2010). Thus, we expect that workplace timing for retirement will be positively related to ER.

Moreover, job stress would act as a push factor, due to the fact that abandonment of a negative work environment will be experienced as a relief, as supported by empirical evidence (Wang, 2007). Primary studies showed a wide range of results, from Bacharach et al. (2008), who found a relationship between job satisfaction and ER of $r=0.20$, to Savwoir (1986), who reported negative relationships of $r=-0.20$. Regarding job stress and ER relationships, a great deal of variation has been found in empirical data. For instance, Lund and Villadsen (2005) found that workers exposed to low skill discretion and high conflict were more likely to prefer ER, whereas Fernández Muñoz et al. (2010) observed an insignificant value $(r=0.07)$ for the relationship between job stress and ER.

Also high physical strain was associated with very high ER intention (Sejbaek et al., 2012). The results of the study of von Bonsdorff et al. (2010a,b) showed that poor work ability, frequent emotional exhaustion, low organizational commitment, and low job control were associated with the prevalence of ER intentions among aging employees. Siegrist et al. (2006) found that poor quality of work is significantly associated with intended ER; after adjustment for well-being, odds ratios (OR) of effortreward imbalance [OR $1.72(1.43-2.08)$ ] and low control at work [OR 1.51 (1.27-1.80)] on intended ER were observed. However, most of the studies of job-related predictors of ER intention are fragmentary, as they only consider isolated factors such as autonomy, organizational climate, workload, supervisory fairness, or opportunities for career development. One study (Schreurs et al., 2011) attempted to overcome these limitations by using as a theoretical framework, the job demands-resources model, also distinguishing between blue-collar and white-collar workers. Its results showed that the relationship between job resources and work enjoyment is stronger among blue-collar workers, whereas the relationship between job demands and ER intentions is stronger among white-collar workers. Schreurs et al. 
considered that the use of the job demands-resources model builds on two types of job-related factors (job resources and job demands), and two processes (an energetic and a motivational process) and offered valuable new insights into how the work environment affects the ER decision process. The results obtained by Elovainio et al. (2005) showed that (high) job demands and (low) job control are independent predictors of ER thoughts and offer additional support for the interaction effect of both factors on ER thoughts. Therefore, we expect that job stress will be positively related to ER.

As ER is a crucial event in the employment trajectory, personjob factors are very relevant as antecedent correlates. In this sense, positive attitudes toward the job, such as high satisfaction, would act as pull factors, influencing the individual decision to delay retirement (i.e., Zappalà et al., 2008). Inversely, normal affective organizational commitment was associated with very high ER intention (Sejbaek et al., 2012). Other studies note that work dissatisfaction influences the decision to exit the organization but not the labor market, so there is no direct effect on ER intentions (Perera et al., 2014). We expect that job satisfaction will be negatively related to ER.

Summing up, although a large part of the studies tend to adopt a dichotomous approach to the antecedent correlates of ER (such as health vs. wealth, push vs. pull factors, voluntary vs. involuntary, or own choice vs. no choice), in fact, it seems that the decision is often fraught with shades of ambiguity and involves considerations at several levels of family-, work-, and job-related factors, in addition to individual factors (Robertson, 2000).

\section{INDIVIDUAL FACTORS}

Seminal reviews (Talaga and Beehr, 1989) and a large amount of empirical evidence (e.g., Bazzoli, 1985; Bingefors and Isacson, 2004; Karpansalo et al., 2005; Eberhardt, 2006; Topa et al., 2009; van Dam et al., 2009) supported that, at the individual level, economic and health factors are the most important variables affecting ER.

First, considering that retirement implies a decision related to spending material wealth and savings, it is not surprising that employees with higher incomes will make fewer decisions to retire early (Zappalà et al., 2008). Despite these objective measures of income, subjective measures must also be taken into account (Topa et al., 2011). Financial security would lead to an increased disposition to early withdrawal from the labor market. According to Taylor and Geldhauser (2007), people tend to deny the information about their future financial difficulties in retirement. This bias would account for the different relationships between objective and subjective measures of income, on the one hand, and ER on the other. But even in this pattern of relations between individual factors and ER, there are notable discrepancies in the empirical evidence. Whereas Zappalà et al. (2008) showed that respondents with a better financial situation preferred to postpone retirement, van Dam et al. (2009) reported a positive relationship between adequate financial situation and $\operatorname{ER}(r=0.21)$.
Second, most of the primary studies on ER included health, both physical and mental, as a predictor, agreeing that poor health should be considered a powerful determinant of ER (Lawless, 2015). The previous meta-analysis (van den Berg et al., 2010) supported this conclusion, based on general population longitudinal studies. Despite this consensus, primary studies showed inconsistent data. For instance, Leinonen et al. (2016) found (in Finnish older workers) that offering choice about the timing of retirement makes poor health a weaker predictor of ER, because it encourages healthy workers to choose ER regardless of the economic incentives provided to continue working, and Zappalà et al. (2008) only ascertained an irrelevant correlation between health and ER preferences $(r=-0.06)$. Thus, regarding economic factors, we expect that income will be negatively related to ER, and financial security will be positively related to ER. Regarding health factors, we expect that both poor physical health and poor mental health will be positively related to ER.

\section{SUBSEQUENT CORRELATES OF ER}

Whereas various authors have proposed extensive models of the antecedent correlates of ER, the study of its subsequent correlates is still fragmentary, despite its being a topic that very quickly aroused the interest of researchers (Owen and Belzung, 1967). The theory that provides background to review subsequent correlates in a more integrated manner is the referred model of Fisher et al. (2016), which discusses ER outcomes at multiple levels, including individual and familial consequences.

\section{INDIVIDUAL SUBSEQUENT CORRELATES}

At lower levels, the subsequent correlates of ER can be conceptualized according to individual factors, which primarily include economic, health, and attitudinal facets. Regarding the former, there is prior consensus about the negative relation between ER and objective income, usually assessed through the pension (Blöndhal and Scarpetta, 1998; Blundell et al., 2002). Despite the fact that, for many years, ER plans were designed with very advantageous conditions, the situation has changed progressively (van Solinge and Henkens, 2007). Moreover, at the beginning of retirement, monthly income very probably exceeds the expenses, but after some years, the expenses begin to exceed the income. The negative relation between ER and financial satisfaction has received theoretical support and increasing empirical evidence. Among other reasons, when people rate their available retirement income positively, they suffer from optimistic bias in their financial planning, so they are unhappy when they reach retirement. The literature revealed a noticeable heterogeneity of findings related to satisfaction. Isaksson (1997) showed an increase in global satisfaction during the first two years after ER, whereas other studies failed to find differences (Herzog et al., 1991).

Regarding the relation between ER and health, there is both theoretical and empirical disagreement. Some authors predict that quitting work will lead to an improvement of physical 
and mental well-being-and even that ER significantly reduces mortality risks (Brockmann et al., 2009)-, whereas others predict harmful effects on health (Ekerdt et al., 1984; van Solinge, 2007; Gallo, 2013) - and even on mortality among male early retirees (Kuhn et al., 2010). Both positions provide supportive empirical results, probably because of the presence of potential moderators, which reveal different patterns or paths to quit the labor market (Wang, 2007). In this sense, other authors note that there is no negative effect of ER on men's health and, if anything, there is a temporary increase in self-reported health and improvements in health in the group of highly qualified workers (Coe and Lindeboom, 2008). Other results (BörschSupan and Schuth, 2014) suggest that ER has negative side-effects on the size and intensity of the retirees' social networks, which, in turn, appear to explain part of the accelerated cognitive aging that occurs after ER.

At a broader level, adjustment and well-being of early retirees include social integration and involvement in leisure activities, both considered as retirement adjustment indicators (van Solinge, 2013). Regarding this point, there is an ongoing debate between those who defend that ER will involve the loss of social relations (e.g., Börsch-Supan and Schuth, 2014), primarily made up of co-workers, clients, and colleagues, and those who consider that people will have more time and, therefore, they will cultivate their relationships with family, relatives and friends, and they will engage in more free-time activities (e.g., van Solinge and Henkens, 2007). Moreover, very large discrepancies among the empirical results have been found, probably due to the influence of the moderator factors, which will be analyzed herein. For instance, Robbins et al. (1994) found that social support in ER did not directly influence adjustment but was associated with increases in goal continuity, which, in turn, was linked to increases in leisure quality and life satisfaction. Vaillant (2002) found that retirement was a source of rewards for men who were able to substitute work relationships with other social contacts. Paul and Batinic (2010) found that, although retirees had less social contact (latent function); it was not associated with less psychosocial well-being or worse mental health. However, Rosenkoetter et al. (2001) found that women were less likely to increase participation in social activities than men. Despite the fact that gender as a moderator will be considered in more detail, conclusions based on meta-analytical findings would be beneficial.

\section{FAMILY-LEVEL SUBSEQUENT CORRELATES}

Lastly, regarding attitudinal subsequent correlates, almost all the works that attempt to appraise retirees' adaptation use measures of general satisfaction or satisfaction with some facet of life (van Solinge, 2013). With regard to satisfaction with life in retirement, it is reasonable to consider that a mismatch between expectations and reality is responsible for the negative relation between ER and life satisfaction. Concerning satisfaction with diverse facets of life in retirement, including intentions of re-employing, finances and health again emerge as important aspects (Pattani et al., 2004).
There is a debate between those who defend that ER is associated with higher satisfaction with health, either because of a real health improvement or a change in attitude, and those who predict less satisfaction, among other reasons, because health complaints become more salient when people no longer have to think about their work (Gallo, 2013). Existing literature showed a complex pattern of relationships, and there are frequent inconsistencies between the empirical results, allowing us to expect potential benefits from applying meta-analytical techniques.

For individual and family-level subsequent correlates, we examine the relationships between ER, on the one hand, and pension, financial satisfaction, physical/mental illness, social engagement, leisure activities participation, and retirement satisfaction, on the other hand, in an exploratory manner.

\section{POTENTIAL MODERATOR VARIABLES}

Most of the studies agree in indicating the important influence of moderating variables in the relationships between ER timing and its antecedent and subsequent correlates (Fisher et al., 2016). Firstly, the existence of very discrepant economic and social situations among different countries leads to large differences in those who opt for ER, depending on the origin of the sample included in the study. Variability is high, and some authors have used the classification of the welfare states provided by EspingAndersen (1999), which distinguishes among Social-democratic and Liberal welfare states. Due to the fact that Social-democratic welfare states grant access to benefits and services based on citizenship, the influence of economic and health factors on ER is expected to be higher. On the contrary, the liberal model is based on private provision, so these citizens need to have strong financial security to take ER.

Secondly, the differences between blue-collar and whitecollar workers are not only based on belonging to different social categories, but also on the tasks and features of the job. Accordingly, white-collar workers have better-paid jobs with different physical and psychological demands, so it is therefore reasonable to expect that the relations between economic variables, health, and ER will differ from those of the bluecollar workers (Artazcoz et al., 2010). As a recent study found (Lawless et al., 2015), non-professional occupational status was significantly associated to ER due to disability among Irish people, showing that there are differences in propensity to retire early by socioeconomic groups. Previous research on blue-collar workers (Szubert and Sobala, 2005) showed that perceived negative work conditions (e.g., repetitive tasks, busy work schedules, or heavy lifting at work) were related to increased trends to accept ER programs.

Thirdly, all the studies coincide in pointing out the importance of the voluntary nature of ER and its influence on short- and mid-term outcomes (Shultz et al., 1998). Lack of voluntary decision is associated with loss of control, increase of uncertainty, perception of injustice, and loss of resources, among other underlying processes (Feldman, 2003, 2013; van Solinge, 2006, 2013; Alcover et al., 2012), as well as with a poorer mental health status compared to voluntary retirees (Negrini et al., 2013). 
Fourthly, gender and age are two very important sociodemographic characteristics for ER. The former, gender, is associated with a large quantity of economic, health, and cultural factors. First, women have shorter and discontinuous work careers, with lower wages, so they usually have fewer savings for retirement (Taylor and Geldhauser, 2007). Second, higher percentages of men have jobs with physical overload, whereas women tend to experience depression and anxiety more frequently than men (Piccinelli and Wilkinson, 2000). On another hand, women usually develop more than one social role (workers, wives, mothers, caregivers), which will presumably facilitate their engagement in different types of activities when they quit work, thereby influencing the consequences of ER (Dorfman, 2013). In addition, women who show lower levels of work centrality appear to be more inclined to apply for ER, and are generally more satisfied with retirement than males (Isaksson and Johansson, 2000).

With regard to the second characteristic, age can exert influence through its association with other variables. Regarding economic facets of retirement, age will be associated with time in accumulating earnings, and with organizational penalties imposed on those who retire early. Regarding health issues, age will be associated with physical and mental decline.

Lastly, the year of publication may offer relevant information as a proxy for other variables not collected in the investigation, such as the global economic situation or the evolution of the social policies concerning employment and retirement.

Therefore, we examine the moderator role of study location, voluntariness of ER, demographic sample characteristics (occupation, mean age, percentage of males), and study characteristics (year of publication), in an exploratory manner.

\section{METHOD}

\section{Literature Search and Inclusion Criteria}

Articles published between 1985 and 2016 were identified through computerized databases (Psycinfo, Medline, ERIC, Academic Search Premier and Dissertation Abstracts) using early retirement, disability retirement, and early retirees as keywords. Besides, manual searches of journals that publish retirement research have been conducted, using early retirement and early retirees as keywords. We also contacted informal networks of researchers in the aging-work area by email to request their unpublished papers. This procedure allowed us to obtain two additional manuscripts submitted for publication. We collected a total amount of 471 empirical studies in full text.

The following inclusion criteria have been fulfilled by those papers included in this review: (a) to be an empirical research that includes a sample of early retirees or any empirical measure of ER; (b) to include relationships between ER and its antecedent correlates or its subsequent correlates; (c) to include a Pearson's correlation coefficient or data that would allow us to calculate it. We obtained 151 empirical studies, written in English, French, or Spanish, containing a total amount of 706,937 participants, with a mean sample size of 4,183 participants $(S D=12,940.1)$ and 380 independent effect sizes (ESs), which included 171 independent samples. Both cross sectional and longitudinal papers have been included, as well as those using data from large panel studies. The number of studies screened, assessed for eligibility, and included in the review is provided in the flow diagram (see Figure 2) according to Preferred Reporting Items for Systematic Reviews and Meta-Analyses (PRISMA) recommendations (Moher et al., 2010).

In the phase of record screening, we discarded theoretical papers, qualitative research and those papers devoted to policy recommendations. Then, in a second phase, we screened full text retrieved studies. We discarded those focused on intended ER, subjective expectations, probabilities or preferences for early exit (e.g., Kim and Feldman, 1998; Isaksson and Johansson, 2000; Pienta and Hayward, 2002; Siegrist et al., 2006; Zappalà et al., 2008, among others; Taylor et al., 2014), and studies which their samples partially overlap with another included study. Some studies were excluded due to absence of sufficient data to obtain a Pearson correlation coefficient (Quick and Moen, 1998; Raymo et al., 2011). Additional reasons to discard full text retrieved studies have been the absence of information on the specific relationships between antecedent or subsequent correlates and ER (e.g., Lawless et al., 2015). Non-English articles were included but only if English-language translations were available.

\section{Coding of Studies}

Among the ER antecedent correlates, we coded family-level (family pull), work-related (organizational pressures, workplace timing for retirement, job stress, and job satisfaction), and individual factors, both economic and health, (income, financial security, poor physical health, poor mental health). Among the ER subsequent correlates, we coded family-level factors (retirement satisfaction), and individual subsequent correlates [economic, health and attitudinal factors (pension, financial satisfaction, mental/physical illness, involvement in leisure activities, and social participation)]. As previous studies have shown different patterns of relationships between objective and subjective measures of income and antecedents and consequences (Taylor and Geldhauser, 2007), we coded these factors separately. We considered income as objective income, whereas financial security included affectively loaded measures such as financial concerns, among others.

Six potential categorical and continuous moderating variables were coded: (a) methodological variables of the sample: participants' occupational categories (white collar, blue collar), participants' perception of ER (voluntary, forced and disabled), gender of the sample (more or $<50 \%$ of males) and participants' age (over 55 years, under 55 years); and (b) contextual variables: study location (North America, European Union, other) and year of publication or completion. The study location was then used to conduct analyses as a function of the welfare states' classification. Due to the fact that the structure of the State and its economic basis have strong relationships with the conditions under which ER is taken, the study location brings the opportunity to consider this data as moderator variable. The process was carried out by two independent raters who, after being trained in the procedure, analyzed $40 \%$ of the studies and reached an acceptable agreement level $(r=0.85)$. The coding manual has been reviewed when 


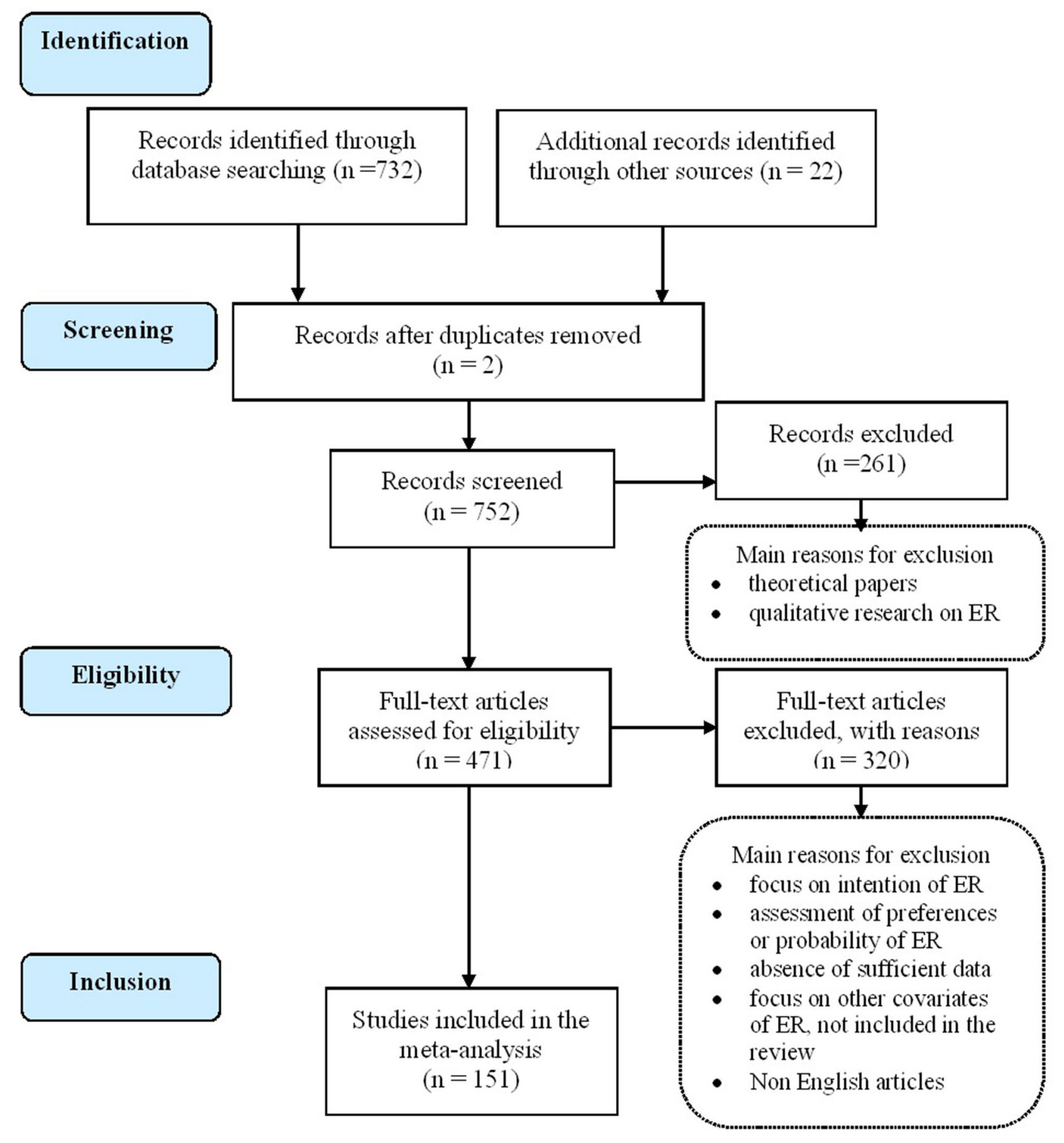

FIGURE 2 | Flow diagram.

discrepancies arise in order to solve them. In order to ensure independence of ES, we retained only one ES per sample. When a single study included two or more independent samples (e.g., public vs. private employees, men vs. women, voluntary vs. involuntary retirees), we included their results as independent studies (e.g., Shultz et al., 1998).
In this meta-analysis, the ES was Pearson's correlation coefficient $(r)$. ES values have been treated with Comprehensive Meta-analysis 2.0 (CMA; Borenstein et al., 2005) in order to be converted to Fisher's $Z$ transformation of $r$. The guideline to interpret the magnitude of ES was $r<0.20=$ low ES value, $r$ between 0.20 and $0.30=$ medium $E S$ value, and 
$r>0.30=$ high (Hemphill, 2003: 78). The 95\% confidence interval was we also reported. Homogeneity analyses were carried out with Q statistics (Hunter and Schmidt, 1990). Due to its shortcoming of poor power when a small number of studies are included, we provide $I^{2}$. The $I^{2}$ index can be interpreted as the percentage of the total variability in a set of ESs due to true heterogeneity (Borenstein et al., 2015). We analyzed the influence of moderator variables using a categorical model (analogousANOVA) and weighted regression analysis (mixed effects model), as recommended by Quintana (2015). Regarding publication bias, different indices are provided. Publication bias occurs because unpublished research with non-significant findings is less available and because journals' practices tend to favor studies with significant findings. As inspection of funnel plot asymmetry (Sterne et al., 2005) seems to be insufficient, different indices should be used to examine the presence of publication bias. In the present study, we included the more classic Fail Safe N proposed by Rosenthal (1979), the Rank correlation test proposed by Begg and Mazumdar (1994), Egger's (Egger et al., 1997) Test of the intercept and Duval and Tweedie's (2000) Trim and Fill test.

We did not exclude studies as outliers for two reasons. First, there is no agreement on the percentage of ES that should be excluded (Hedges and Olkin, 1985). Second, the exclusion of outliers made it problematic to test for differences among categories of moderator variables.

\section{RESULTS}

\section{Description of Studies}

The 151 studies have been performed or published before 2016 (11 between 1985 and 1995, 11 between 1996 and 2000, 31 between 2001 and 2005, and 98 between 2006 and 2014). Most studies were conducted in the European Union (104) and in the United States of America (39), and the remaining studies included participants from Asia, Australia, or Canada. The mean age of the sample was 56.68 years $(S D=7.77)$. The mean percentage of males in the samples was $60.81 \%(S D=35.67)$.

\section{Antecedent Correlates of ER: Mean ES}

Family pull exerted a positive influence on ER, reaching an average low level ES ( $r=0.19$, CI [0.09, 0.29]). Both organizational pressures and workplace timing for retirement exhibited positive relationships with ER (Table 1), with workplace timing for retirement showing an average ES of medium level $(r=0.25$, CI $[0.17,0.33])$, and organizational pressures $(r=0.22$, CI $[0.15,0.29])$ reached a medium level ES. The correlation was much larger for the workplace timing-ER relationship than for the organizational pressures-ER, despite the fact that their CIs substantially overlapped. Job stress reached a positive mean low level ES ( $r=0.16$, CI $[0.12,0.20])$, with a lower level size. Job satisfaction-ER relationships were negative, with lower levels values ( $r=-0.16$, CI $[-0.20,-0.11])$.

Finally, income-ER exhibited a negative relationship, with a mean lower level ES of $r=-0.13$. At the same time, financial security reached a medium level ES $(r=0.22$, CI $[0.16,0.28])$. A positive relationship between previous poor health, both physical $(r=0.20$, CI $[0.16,0.24])$, and mental $(r=0.20$, CI $[0.15,0.25])$ was obtained (see Table 1).

\section{Subsequent Correlates of ER and Mean ES}

We expected significant relationships between ER and both economic and health subsequent correlates. A mean ES of low level for the relationship between ER and pension $(r=0.18$, CI $[0.07,0.29])$ was obtained, whereas the relationship between ER and financial satisfaction showed also a lower level ES $(r=-0.15$, CI $[-0.24,0.06])$, and their CIs did not substantially overlap. The relationship between illness and ER only reached a lower level ES $(r=0.08$, CI $[-0.02,0.18])$. Our findings showed a medium mean ES for social engagement $(r=-0.25$, CI $[-0.47,-0.04])$, and a lower ES for participation in leisure activities $(r=0.12, \mathrm{CI}$ $[0.03,0.22])$. And, finally, a lower level ES ( $r=0.12$, CI $[-0.16$, $0.39])$ was also reached for retirement satisfaction.

\section{Publication Bias Analyses}

Firstly, related to publication bias, Classic Fail Safe N, which is large in all of our meta-analyses, allows us to feel confident that the treatment effect, while possibly inflated by the exclusion of some studies, is nevertheless not null. Despite the fact that researchers stated that Fail-Safe $\mathrm{N}$ exceeding five times the number of included effects would indicate robust effect, we acknowledge that some of our meta-analyses have a small $k$, and we continued exploring potential bias by additional tests. Secondly, we applied Begg and Mazumdar's (1994) Rank correlation test, which provides Kendall's tau b-value, and which suggests that publication bias exists if the associated $p$-value is statistically significant $(p<0.05)$. With this test, we found that the job stress-ER and poor physical health-ER meta-analyses might be biased (see Table 2).

Thirdly, as this approach is still limited, due to the fact that its power is moderate for smaller meta-analyses, we used an alternative test. Egger's (Egger et al., 1997) test is best suited for smaller meta-analyses ( $k<25$ studies). This test uses a regression model to predict the standardized ES, and the intercept of the regression is the bias. Consequently, a $t$-value, with a $p<$ 0.001 is offered as an indicator of potential publication bias. When applying this procedure, we found that the organizational pressures-ER, job stress-ER, poor physical and poor mental health-ER, and leisure activities -ER meta-analyses would be affected by publication bias. Finally, when there is evidence of publication bias, a method can be used to adjust the metaanalytical estimations and provide a reasonable estimate of how many studies are missing. The Trim and Fill method may slightly overestimate missing studies, but it can be used to assess the potential impact of these probable studies on the ES (Quintana, 2015).

According to these findings, we contend that the point estimate under the random effects model would be smaller for seven meta-analyses (Family Pull, Organizational pressures, Workplace Timing for retirement, Job stress, Financial security, Poor mental Health, Leisure activities participation, and Retirement satisfaction). These point estimates should not be used to support any conclusion, as, based on these previous analyses, we consider that publication bias is a potential concern 
TABLE 1 | Mean weighted effect sizes for meta-analysis.

\begin{tabular}{|c|c|c|c|c|c|c|c|}
\hline \multirow[t]{2}{*}{ Variables } & \multirow[t]{2}{*}{$k$} & \multirow[t]{2}{*}{ Weighted $r$} & \multirow[t]{2}{*}{$S D$} & \multicolumn{2}{|c|}{$95 \% \mathrm{Cl}$} & \multirow[t]{2}{*}{$Q$ (df) } & \multirow[t]{2}{*}{$I^{2}$} \\
\hline & & & & LI & UI & & \\
\hline \multicolumn{8}{|l|}{ ANTECEDENT CORRELATES } \\
\hline \multicolumn{8}{|c|}{ Family-level antecedent correlates } \\
\hline Family pull & 19 & 0.19 & 0.05 & 0.09 & 0.29 & $739.13(18)^{\star \star \star}$ & 97.5 \\
\hline \multicolumn{8}{|c|}{ Work-related antecedent correlates } \\
\hline Organizational pressures & 20 & 0.22 & 0.04 & 0.15 & 0.29 & $864.22(19)^{\star \star \star}$ & 97.8 \\
\hline Workplace timing for retirement & 9 & 0.25 & 0.04 & 0.17 & 0.33 & $99.2(8)^{\star \star \star}$ & 91.9 \\
\hline Job stress & 27 & 0.16 & 0.02 & 0.12 & 0.20 & $391.5(26)^{\star \star \star}$ & 93.4 \\
\hline \multicolumn{8}{|c|}{ Person-job antecedent correlates } \\
\hline Job satisfaction & 27 & -0.16 & 0.02 & -0.20 & -0.11 & $851.68(26)^{\star \star \star}$ & 96.9 \\
\hline \multicolumn{8}{|l|}{ Individual factors } \\
\hline Income & 24 & -0.13 & 0.03 & -0.18 & -0.07 & $2,298.7(23)^{\star \star \star}$ & 98.9 \\
\hline Financial security & 27 & 0.22 & 0.03 & 0.16 & 0.28 & $585.75(26)^{\star \star \star}$ & 95.56 \\
\hline Poor physical health & 109 & 0.20 & 0.02 & 0.16 & 0.24 & $23,669.9(108)^{\star \star \star}$ & 99.5 \\
\hline Poor mental health & 41 & 0.20 & 0.02 & 0.15 & 0.25 & $864.6(40)^{\star \star \star}$ & 95.37 \\
\hline \multicolumn{8}{|l|}{ SUBSEQUENT CORRELATES } \\
\hline \multicolumn{8}{|l|}{ Individual subsequent correlates } \\
\hline Pension & 20 & 0.18 & 0.05 & 0.07 & 0.29 & $1,861.68(19)^{\star \star \star}$ & 98.98 \\
\hline Financial satisfaction & 11 & -0.15 & 0.05 & -0.24 & 0.06 & $73.63(10)^{\star \star \star}$ & 86.42 \\
\hline Mental/Physical IIIness & 12 & 0.08 & 0.05 & -0.02 & 0.18 & $307.37(11)^{\star \star \star}$ & 96.42 \\
\hline Social engagement & 4 & -0.25 & 0.11 & -0.47 & -0.04 & $27.67(3)^{\star \star \star}$ & 89.16 \\
\hline Leisure activities & 8 & 0.12 & 0.05 & 0.03 & 0.20 & $66.26(7)^{\star \star \star}$ & 89.44 \\
\hline \multicolumn{8}{|c|}{ Family-level subsequent correlates } \\
\hline Retirement satisfaction & 10 & 0.12 & 0.14 & -0.16 & 0.39 & $1,837.51(9)^{\star \star \star}$ & 98.77 \\
\hline
\end{tabular}

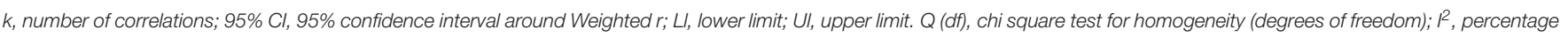
of variance beyond the sampling error. ${ }^{* \star} p<0.001$.

with these data. Despite this fact, Sterne et al. (2005) acknowledge that these analyses may be inaccurate when there is substantial between-study variability.

\section{Potential Moderator Variables}

Table 1 shows the results for the $Q$ statistics analyses and $I^{2}$. Both values revealed significant heterogeneity across studies, with percentages of explained variance due to this heterogeneity ranging from $86 \%$ for the ER-financial satisfaction relationship to $99.6 \%$ for poor physical health-ER. In view of these results, we explored potential moderator variables using a categorical model (analogous ANOVA) and weighted regression analysis (random effects model).

Table 3 shows the results of moderator analyses as a function of the origin of the sample. We expected that welfare states would have effects on individual factors-ER relationships. Regarding the income-ER relationship, the correlation was much larger for studies from countries with a Social-democratic welfare state than for those from Liberal welfare states, despite the fact that their CIs substantially overlapped. Results showed that financial security ES seems to be similar for participants from Liberal and Social democratic welfare states. Regarding the poor physical health-ER relationship, both $Q_{(b)}$ and $Q_{(w)}$ reached statistical significance, showing that a greater level of heterogeneity remained unexplained by the analyses. The mean ES for each category showed higher values for Social-democratic welfare states, despite that the CIs substantially overlapped. Moreover, considering the poor mental health-ER relationship, the mean ES distinguished participants from Liberal welfare states, with higher values than those from Social-democratic welfare states. Finally, regarding ER-pension relationships, the mean ESs showed lower values for participants from countries with Liberal welfare states.

Related to the participants' labor status, the ES showed differences between blue- and white-collar workers both in the individual-ER and in the job stress-ER relationships. Despite the fact that their CIs substantially overlapped, our results showed that the negative correlation between income and ER was much larger for studies with blue-collar workers than for white-collar workers. Both $Q_{(b)}$ and $Q_{(w)}$ reached significant values for the financial security-ER relationship, and similar ES values were reached for blue-collar workers as for white-collar workers. We expected differences in the relationship between poor physical health-ER among blue- and white-collar retirees, and the results provided support for this expectation. Although not addressed in our predictions, we observed that poor physical health effects on ER were moderated by participants' occupational categories ( $r=0.16$ vs. $r=0.22$ for white- vs. blue-collar). Regarding the 
TABLE 2 | Publication biasindices.

\begin{tabular}{|c|c|c|c|c|}
\hline Variables & $\begin{array}{c}\text { Classic } \\
\text { fail-safe } N\end{array}$ & $\begin{array}{c}\text { Rank correlation test } \\
\text { (Kendall's tau b; } \\
\text { p-value }{ }^{\text {a) }}\end{array}$ & Egger's test & $\begin{array}{l}\text { Duval and tweedie's trim and } \\
\text { fill (Random effects model } \\
\text { point estimate and } 95 \% \mathrm{Cl} \text { ) }\end{array}$ \\
\hline \multicolumn{5}{|l|}{ ANTECEDENT CORRELATES } \\
\hline \multicolumn{5}{|c|}{ Family-level antecedent correlates } \\
\hline Family pull & 1,398 & $0.70 ; p=0.34$ & Intercept $=3.67 ; t=1.58 ; d f=17 ; p=0.06$ & $0.04(-0.07 ; 0.16)$ \\
\hline \multicolumn{5}{|c|}{ Work-related antecedent correlates } \\
\hline Organizational pressures & 2,734 & $0.06 ; p=0.36$ & Intercept $=5.57 ; t=2.96 ; d f=18 ; p=0.001$ & $0.05(-0.03 ; 0.13)$ \\
\hline Workplace timing for retirement & 984 & $0.36 ; p=0.09$ & Intercept $=4.76 ; t=1.39 ; d f=7 ; p=0.10$ & $0.19(0.10 ; 0.28)$ \\
\hline Job stress & 3,824 & $0.26 ; p=0.03$ & Intercept $=3.14 ; t=2.71 ; d f=25 ; p=0.00$ & $0.07(0.03 ; 0.12)$ \\
\hline \multicolumn{5}{|c|}{ Person-job antecedent correlates } \\
\hline Job satisfaction & 7,105 & $-0.09 ; p=0.25$ & Intercept $=-1.62 ; t=0.87 ; d f=25 ; p=0.20$ & Values are unchanged. \\
\hline \multicolumn{5}{|l|}{ Individual factors } \\
\hline Income & 2,348 & $0.05 ; p=0.35$ & Intercept $=-4.03 ; t=1.87 ; d f=22 ; p=0.04$ & Values are unchanged. \\
\hline Financial security & 4,461 & $0.12 ; p=0.19$ & Intercept $=3.03 ; t=2.31 ; d f=25 ; p=0.02$ & $0.10(0.03 ; 0.17)$ \\
\hline Poor physical health & 988,789 & $0.36 ; p=0.00$ & Intercept $=-6.31 ; t=4.76 ; d f=106 ; p=0.00$ & Values are unchanged. \\
\hline Poor mental health & 8,288 & $-0.12 ; p=0.14$ & Intercept $=2.33 ; t=2.38 ; d f=39 ; p=0.01$ & $0.12(0.07 ; 0.17)$ \\
\hline \multicolumn{5}{|l|}{ SUBSEQUENT CORRELATES } \\
\hline \multicolumn{5}{|c|}{ Individual subsequent correlates } \\
\hline Pension & 4,063 & $-0.06 ; p=0.72$ & Intercept $=0.21 ; t=0.05 ; d f=18 ; p=0.48$ & Values are unchanged. \\
\hline Financial satisfaction & 222 & $0.13 ; p=0.29$ & Intercept $=1.24 ; t=0.58 ; d f=9 ; p=0.29$ & Values are unchanged. \\
\hline Mental/physical illness & 428 & $-0.05 ; p=0.42$ & Intercept $=-1.58 ; t=0.79 ; d f=10 ; p=0.22$ & Values are unchanged. \\
\hline Social engagement & 55 & $0.50 ; p=0.15$ & Intercept $=8.28 ; t=0.98 ; d f=2 ; p=0.22$ & $-0.33(-0.54 ;-0.12)$ \\
\hline Leisure activities & 43 & $-0.04 ; p=0.45$ & Intercept $=3.26 ; t=3.35 ; d f=6 ; p=0.007$ & $-0.02(-0.09 ; 0.06)$ \\
\hline \multicolumn{5}{|c|}{ Family-level subsequent correlates } \\
\hline Retirement satisfaction & 305 & $0.40 ; p=0.05$ & Intercept $=4.25 ; t=0.70 ; d f=8 ; p=0.25$ & $-0.06(-0.33 ; 0.21)$ \\
\hline
\end{tabular}

${ }^{a} p$-value based on continuity-corrected normal approximation.

TABLE 3 | Weighted analysis of variance as a function of origin of the sample.

\begin{tabular}{|c|c|c|c|}
\hline \multirow[t]{2}{*}{ Variables } & \multirow[t]{2}{*}{$Q b(d f) / Q w(d f)$} & \multicolumn{2}{|c|}{ Effect size (LI/UI) } \\
\hline & & Liberal & Social democratic \\
\hline \multicolumn{4}{|c|}{ ANTECEDENT CORRELATES } \\
\hline Income-ER & $74.6(1)^{\star \star \star} / 2,224.1(22)^{\star \star \star}$ & $-0.08(-0.14 /-0.03)$ & $-0.17(-0.27 /-0.07)$ \\
\hline Financial security-ER & $8.55(1)^{\star \star \star} / 577.21(25)^{\star \star \star}$ & $0.22(0.13 / 0.31)$ & $0.22(0.13 / 0.32)$ \\
\hline Poor physical health-ER & $12,010.7(1) / 11,511.7(105)^{\star \star \star}$ & $0.16(0.07 / 0.25)$ & $0.23(0.19 / 0.25)$ \\
\hline Poor mental health-ER & $48.52(1)^{\star \star \star} / 816.1(39)^{\star \star \star}$ & $0.18(0.09 / 0.28)$ & $0.21(0.16 / 0.26)$ \\
\hline \multicolumn{4}{|c|}{ SUBSEQUENT CORRELATES } \\
\hline ER-Pension & $297.2(1)^{\star \star \star} / 1,564.4(17)^{\star \star \star}$ & $0.10(-0.08 / 0.29)$ & $0.25(0.15 / 0.35)$ \\
\hline
\end{tabular}

Qb (df)/Qw: chi square test for homogeneity between and within (degrees of freedom); ${ }^{\star \star \star} p<0.001$.

ER-pension relationships, our findings showed that the ES was much larger for studies with white-collar participants than for those with blue-collar workers (see Table 4).

We expected that voluntariness of ER would play a moderator role in the individual factors-ER and in the ERsubsequent correlates relationships. Table 5 shows the results of the analogous ANOVA as a function of the perception of forced retirement. Disabled workers were considered a different category, and data are provided when we found sufficient information among the primary studies. Regarding antecedent correlates of ER, the findings showed higher values for the negative income-ER relationship among forced retirees than for voluntary ones, despite the fact that both $Q_{(b)}$ and $Q_{(w)}$ reached statistical significance. The effect of financial security on ER was moderated by voluntariness, such that a small ES was shown for forced retirees whereas a large ES was exhibited for voluntary retirees.

In the case of poor physical health, both $Q_{(b)}$ and $Q_{(w)}$ reached significance, and the higher value was shown by disabled retirees. As Table 5 shows, the larger ES was exhibited for disabled retirees 
TABLE 4 | Weighted analysis of variance as a function of participants' occupational categories.

\begin{tabular}{|c|c|c|c|}
\hline \multirow[t]{2}{*}{ Variables } & \multirow[t]{2}{*}{$Q b(d f) / Q w(d f)$} & \multicolumn{2}{|c|}{ Effect Size (LI/UI) } \\
\hline & & White collar & Blue collar \\
\hline \multicolumn{4}{|c|}{ ANTECEDENT CORRELATES } \\
\hline Job stress-ER & $79.7(1)^{\star \star \star} / 311.9(25)^{\star \star \star}$ & $0.14(0.09 / 0.19)$ & $0.19(0.13 / 0.25)$ \\
\hline Income-ER & $38.74(1)^{\star \star \star} / 2,259.9(22)^{\star \star \star}$ & $-0.08(-0.19 /-0.02)$ & $-0.15(-0.22 /-0.07)$ \\
\hline Financial security-ER & $16.6(1)^{\star \star \star} / 569.03(24)^{\star \star \star}$ & $0.22(0.15 / 0.29)$ & $0.20(-0.09 / 0.51)$ \\
\hline Poor physical health-ER & $595.3(1)^{\star \star \star} / 23,049.7(105)^{\star \star \star}$ & $0.16(0.08 / 0.24)$ & $0.22(0.17 / 0.26)$ \\
\hline \multicolumn{4}{|c|}{ SUBSEQUENT CORRELATES } \\
\hline ER-Pension & $141.61(1)^{\star \star \star} / 1720.07(18)^{\star \star \star}$ & $0.32(-0.15 / 0.80)$ & $0.15(0.06 / 0.24)$ \\
\hline
\end{tabular}

$\mathrm{Qb}(d f) / Q w$ : chi square test for homogeneity between and within (degrees of freedom); ${ }^{\star \star \star} p<0.001$.

TABLE 5 | Weighted analysis of variance as a function of participants' perception of forced retirement.

\begin{tabular}{|c|c|c|c|c|}
\hline \multirow[t]{2}{*}{ Variables } & \multirow[t]{2}{*}{$Q b(d f) / Q w(d f)$} & \multicolumn{3}{|c|}{ Effect size (LI/UI) } \\
\hline & & Voluntary & Forced & Disabled \\
\hline \multicolumn{5}{|c|}{ ANTECEDENT CORRELATES } \\
\hline Income-ER & $33.9(2)^{\star \star \star} / 2,264.7(21)^{\star \star \star}$ & $-0.04(-0.10 / 0.02)$ & $-0.16(-0.23 /-0.9)$ & $-0.02(-0.07 / 0.04)$ \\
\hline Financial security-ER & $120.9(1)^{\star \star \star} / 464.8(24)^{\star \star \star}$ & $0.34(0.05 / 0.62)$ & $0.19(0.14 / 0.24)$ & $-0.07(-0.45 / 0.32)$ \\
\hline Poor physical health-ER & $914.31(2)^{\star \star \star} / 22,752.7(105)^{\star \star \star}$ & $0.20(0.16 / 0.25)$ & $0.05(-0.07 / 0.17)$ & $0.26(0.14 / 0.37)$ \\
\hline Poor mental health-ER & $0.53(2) / 864.10(34)^{\star \star \star}$ & $0.23(0.17 / 0.28)$ & $0.11(0.002 / 0.23)$ & $0.07(-0.07 / 0.21)$ \\
\hline \multicolumn{5}{|c|}{ SUBSEQUENT CORRELATES } \\
\hline ER-Pension & $284.79(1)^{\star \star \star} / 1,576.9(18)^{\star \star \star}$ & $0.20(0.09 / 0.30)$ & $-0.17(-0.21 /-0.13)$ & n. a. \\
\hline ER-Retirement satisfaction & $0.58(1) / 272.85(4)^{\star \star \star}$ & $0.24(-0.14 / 0.63)$ & $-0.10(-0.97 / .073)$ & n. a. \\
\hline
\end{tabular}

Qb (df)/Qw: chi square test for homogeneity between and within (degrees of freedom); ${ }^{\star \star \star} p<0.001 ; n$. a., not available.

than for voluntary and forced ones, despite that the values were similar and the CIs substantially overlapped. Related to poor mental health, the data showed larger values for voluntary retirees than for forced or even for disabled ones.

We expected that gender would play a moderator role in the individual factors-ER relationships. On the one hand, our findings showed that ES was larger for males than for females in the income-ER relationships but not in the financial security-ER relationships. On the other hand, females showed a stronger ES for poor health, both physical and mental, than males. Regarding subsequent correlates of ER, males exhibited higher values than females in the ER-pension relationships (see Table 6).

We expected that participants' age would act as a moderator both of the individual factors-ER and the ER- subsequent correlates relationships. Our findings showed that studies with participants aged over 55 years obtained larger ESs in the incomeER relationships, compared with those with participants aged below 55 years. This pattern of results was also exhibited for the financial security-ER relationship. Regarding poor physical health, participants aged over 55 years showed smaller ESs than younger participants. For the poor mental health-ER relationship, the opposite was observed. Finally, regarding ERpension relationships, our findings exhibited larger ES values for younger participants than for older respondents (see Table 7).

Weighted regression analyses were used to test the influence of the unique quantitative variable, year of publication. We expected that relationships between antecedent correlates-ER and ERsubsequent correlates would be affected by year of publication. The results provided mixed support for this prediction. Considering year of publication, the results revealed a highly significant $Q_{E}$ in many cases (income-ER, poor physical healthER, poor mental health-ER, and ER-pension) and, in contrast, $Q_{R}$ failed to reach significant values. As a consequence, the $R^{2}$ analog values were negligible in these analyses. Regarding financial security-ER, results seem to be more promising $\left(R^{2}\right.$ $=0.10$ ), despite that only $Q_{E}$ was statistically significant (see Table 8).

\section{DISCUSSION}

The present meta-analysis was aimed to synthesize the results of the empirical studies of ER and to meta-analytically test a theoretical model of its antecedent and subsequent correlates derived from the Fisher et al. (2016) Model. The procedure has been developed in three steps: first, separate meta-analyses of ERits antecedent and subsequent correlates have been conducted. Second, analyses of potential moderating variables have been conducted in order to offer some explanation for the variability between empirical findings. Some analyses were based on a restricted number of primary researches, but the results allowed us to reach several conclusions based on the empirical findings. Our findings can be seen as a research tool that allows us to 
TABLE 6 | Weighted analysis of variance as a function of participants' gender.

\begin{tabular}{|c|c|c|c|}
\hline \multirow[t]{2}{*}{ Variables } & \multirow[t]{2}{*}{$Q b(d f) / Q w(d f)$} & \multicolumn{2}{|c|}{ Effect Size (LI/UI) } \\
\hline & & Females & Males \\
\hline \multicolumn{4}{|c|}{ ANTECEDENT CORRELATES } \\
\hline Income-ER & $420.9(1)^{\star \star \star} / 1,877.7(22)^{\star \star \star}$ & $-0.09(-0.14 /-0.03)$ & $-0.17(-0.38 / 0.05)$ \\
\hline Financial security-ER & $49.5(1)^{\star \star \star} / 536.3(25)^{\star \star \star}$ & $0.24(0.14 / 0.35)$ & $0.18(0.12 / 0.25)$ \\
\hline Poor physical health-ER & $1,807.39(1)^{\star \star \star} / 21,859.7(106)^{\star \star \star}$ & $0.21(0.16 / 0.26)$ & $0.19(0.14 / 0.24)$ \\
\hline Poor mental health -ER & $6.09(1)^{\star} / 858.5(39)^{\star \star \star}$ & $0.22(0.16 / 0.29)$ & $0.17(0.09 / 0.24)$ \\
\hline \multicolumn{4}{|c|}{ SUBSEQUENT CORRELATES } \\
\hline ER-Pension & $14.48(1)^{\star \star \star} / 1,847.2(18)^{\star \star \star}$ & 0.15 (0.02/0.27) & $0.20(-0.001 / 0.39)$ \\
\hline
\end{tabular}

$\mathrm{Qb}(d f) / \mathrm{Qw}$ : chi square test for homogeneity between and within (degrees of freedom); ${ }^{\star} p<0.05 .{ }^{* \star *} p<0.001$.

TABLE 7 | Weighted analysis of variance as a function of participants' age.

\begin{tabular}{|c|c|c|c|}
\hline \multirow[t]{2}{*}{ Variables } & \multirow[t]{2}{*}{$Q b(d f) / Q w(d f)$} & \multicolumn{2}{|c|}{ Effect size (LI/UI) } \\
\hline & & Below 55 years & Over 55 years \\
\hline \multicolumn{4}{|c|}{ ANTECEDENT CORRELATES } \\
\hline Income-ER & $372.4(1)^{\star \star \star} / 1,926.3(22)^{\star \star \star}$ & $-0.05(-0.11 / 0.02)$ & $-0.19(-0.32 /-0.05)$ \\
\hline Financial security-ER & $1.41(1) / 584.2(24)^{\star \star \star}$ & $0.17(0.12 / 0.22)$ & $0.24(0.13 / 0.36)$ \\
\hline Poor physical health-ER & $12,888.1(1)^{\star \star \star} / 10,778.9(106)^{\star \star \star}$ & $0.22(0.18 / 0.25)$ & $0.18(0.11 / 0.25)$ \\
\hline Poor mental health -ER & $226.01(1) / 638.6(39)^{\star \star \star}$ & $0.19(0.16 / 0.26)$ & $0.21(0.16 / 0.27)$ \\
\hline \multicolumn{4}{|c|}{ SUBSEQUENT CORRELATES } \\
\hline ER-Pension & $20.61(1) / 1,841.07(18)^{\star \star \star}$ & $0.24(0.03 / 0.46)$ & $0.15(0.01 / 0.28)$ \\
\hline
\end{tabular}

Qb (df)/Qw: chi square test for homogeneity between and within (degrees of freedom); ${ }^{* \star *} p<0.001$.

highlight the overall network of relationships between constructs and to improve our understanding of the retirement process.

What are the main antecedent and subsequent correlates of ER?

First, the weight of the social-normative expectations of ER clearly emerge (Feldman and Beehr, 2011), due to the fact that the variables that entail external pressures from any source showed higher ESs. All things considered, workplace timing of retirement is the best predictor of ER, followed by organizational pressures. Although there are a number of individual, family, and macroeconomic and sociocultural factors that are antecedent correlates of retirement timing, work- and organizational-related factors are two of most relevant (Fisher et al., 2016). Our results confirm previous research, which showed that older workers' social environment (workplace timing and organizational pressures) is related to ER (van Solinge and Henkens, 2007).

These findings underline the relevance of an organizational climate for successful aging for older people's motivation to continue working (Zacher and Yang, 2016). In this sense, if the organization provides a climate for successful aging, older employees would perceive better job opportunities, and these perceptions, in turn, would be positively related to affective commitment and would discourage them from ER (ArmstrongStassen and Schlosser, 2008). In the same line, as a recent study stated (Segura et al., 2017), lack of a healthy environment at work, less autonomy, task significance, variety, and feedback could derive in a loss of meaningfulness, responsibility, and knowledge
TABLE 8 | Weighted multiple regressions as a function of year of publication.

\begin{tabular}{lllr}
\hline Variable & \multicolumn{3}{c}{ Moderator: year of publication } \\
\cline { 2 - 4 } & $\boldsymbol{R}^{\mathbf{2}}$ analog & $\boldsymbol{Q}_{\mathbf{R}}(\boldsymbol{d} \boldsymbol{f})$ & $\boldsymbol{Q}_{\mathbf{E}}(\boldsymbol{d} \boldsymbol{f})$ \\
\hline ANTECEDENT CORRELATES & & & \\
Income- ER & 0.01 & $0.33(1)$ & $1,603.4(22)^{\star \star \star}$ \\
Financial security- ER & 0.10 & $2.72(1)$ & $555.89(25)^{\star \star \star}$ \\
Poor physical health- ER & 0.00 & $0.07(1)$ & $23,622.02(106)^{\star \star \star}$ \\
Poor mental health- ER & 0.03 & $0.81(1)$ & $862.18(39)^{\star \star \star}$ \\
SUBSEQUENT CORRELATES & & & \\
ER- Pension & 0.00 & $0.82(1)$ & $1,614.21(18)^{\star \star \star}$ \\
\hline
\end{tabular}

${ }^{\star * \star} p<0.001$.

for older workers, which could lead to seeking ER. Despite the fact that there are some workers' strategies, such as optimization, which could serve as an additional source of motivation or even as a buffer, it seems very difficult to reduce the negative impact of the unhealthy environment on employee ER.

Second, a cascade effect of person-environment fit levels has been shown, beginning with organizational fit and following with family fit, as various authors suggested (Kristof-Brown et al., 2002; Feldman, 2013). Considering the degree of impact on ER, workplace timing preferences was the first variable, organizational pressures the second, and family pull the last. 
Although an individual's perception of push and pull factors occurs in context, and although an individual's perception of context can lead to the same event being rated as either a push or a pull by different workers (Shultz et al., 1998), it seems that a pattern of relationships exists, as Feldman (2013) suggested. This finding supports the evidence about the impact of positive job characteristics on intended retirement time (Ecklund, 2014), as well as the fact that, although people cannot control the external circumstances affecting the retirement process, they can at least anticipate the conditions of the process by retirement planning and preparation programs (Palaci et al., 2017).

Third, when comparing family-level and person-job antecedent correlates, we realized that poor adjustment between the older workers and their immediate environment has the strongest impact on ER. Family pull, which represents an immediate social cue, exerted more influence on ER than did job satisfaction. Regarding this pattern, we must take into account that ER not only implies losing social relations made up of colleagues and supervisors, but it also offers the possibility of gaining stronger contacts with family. Hence, family and partner involvement are very important to deal with retirement transition (Feldman, 2013), as supported by recent evidence (Topa et al., 2017a; Yeung and Zhou, 2017).

Fourth, regarding ER antecedent correlates at the work/job level, job satisfaction showed the same ES as job stress. As older workers' preferences change from extrinsic to intrinsic rewards, ES in the job satisfaction-ER relationship shows that emotional job attachment would have a similar influence on ER decisions as the job's negative characteristics, which, in turn, would trigger a stress process. As some researchers have recently shown, a work environment with many organizational resources will foster work engagement, which in turn will increase the likelihood of job satisfaction and the intention to stay longer (Guglielmi et al., 2016). But this relationship was shown to be moderated by the joint influence of job demand intensity and age, confirming that different patterns emerge as a function of employees' age (Topa et al., 2016), and socioeconomic characteristics (Davies et al., 2017).

Fifth, within individual ER antecedent correlates, health seems to exert a great influence. Our results also suggest that both physical and mental health have the same impact on ER. The experience of preretirement work stress and a poor psychosocial quality of work (Siegrist et al., 2006) may be related to the perception of poorer health, both physical and mental, such that both act as push factors to ER. Additionally, health seems to exert more influence than objective measures of finances-incomebut not than perceptual measures of financial security. However, it is necessary to take into account that the relationships between health and finances are very complex. Firstly, illness can affect subjective perceptions of income adequacy. This would be due to the fact that these measures were affectively loaded, and poor physical and mental health could bias them (Topa and HerradorAlcaide, 2016). Secondly, health could affect income, due to the fact that illness limits access to better jobs and makes saving more difficult. Lastly, it has been suggested that combinations of stressful events such as financial difficulties can make people more vulnerable when a negative event occurs. In this light, income may be less important for healthier people than for those who have suffered a decline in health.

Regarding economic antecedent correlates of ER, objective measures of income showed less influence than subjective ones. As previous researchers suggested, it is likely that people earning high salaries seek to delay their retirement in order to accumulate earnings that allow them financial freedom (Zappalà et al., 2008), as shown by the negative ES of income. Due to their nature, objective indices of finances may serve as better predictors of the ability to meet financial needs after retirement, whereas affectiveloaded measures would be biased by unrealistic optimism about retirement, as indicated by the positive and stronger ES of financial security. These findings are in line with recent studies that underline the influence of some psychological features that could bias economic information processing (Topa et al., in review). Our results confirm that these phenomena could be related to each other despite that there are not interchangeable. The complexity of our findings highlights the statement of Feldman (2003, p. 281) that "treating the retirement decision as one made solely by the individual on the basis of the earnings may miss a considerable amount of variance in the decision-making process."

Our findings related to the subsequent correlates of ER showed two controversial relations with illness, on the one hand, and pension, on the other, which both remained positive in our meta-analytical results. Although the debate between defenders of the positive and negative effects of ER on health exceeds the scope of this review, our findings provide evidence of the underlying processes. As empirical studies stated (Paul and Batinic, 2010), ER would entail a deterioration of resources that ensure stability, status, and privileged conditions; and of valuable personal resources-self-esteem or social skills-which, and in turn, could have an impact on health (Topa et al., 2017b; Yeung and Zhou, 2017). But, despite the fact that this review could not include a statistical control of the negative influence of previous poor health on later illness-which should be done by a metaanalytic structural equation model-this pattern would exist. Recent research based on a longitudinal study showed a longterm impact of pre-retirement depression on post-retirement depression, besides its influence through the perception of threats during the transition (Topa and Valero, 2017). Does ER have a fatal attraction? As Kuhn et al. (2010) found, death causes indicate a significantly higher incidence of cardiovascular disorders among male early retirees, suggesting that changes in health-related behavior explain increased mortality among males, although they did not find any adverse effect of ER on mortality for females. Although ER has gained an increasingly positive image, the data of this review do not support such an optimistic view.

Regarding the economic subsequent correlates, objective measures-pension-showed a higher impact than subjective ones-financial satisfaction-, contrary to the pattern exhibited in the antecedent correlates section, but these findings must be deeply analyzed in order to detect differences as a function of voluntariness and labor status. Again, it is necessary to recognize that illness and finances have mutual influences, and 
both factors can reduce quality of life in retirement. In this sense, chronic illness can negatively influence satisfaction with income in retirement, not only because it conditions needs assessments, but also because it can eat into the savings actually set aside by the more farsighted retirees, who may see their resources diminished by the rising cost of health services. And, in turn, poor health status and pessimistic financial expectations predict greater household financial distress (Litwin and Sapir, 2009).

Our findings related to the subsequent correlates of ER indicate that the strongest negative impact was on social engagement, which has the highest ES among the ER subsequent correlates. Although maintaining social contact may not only depend on work-related social relations, one of the factors with the greatest influence on the disposition to ER is the expectation of social contact (Henkens and Tazelaar, 1994). Our results indicate that, even considering this expectation, early retirees undergo a significant reduction of social integration, a negative experience that does not seem to be compensated through nonwork activities such as volunteering, family duties, and hobbies (Kim and Feldman, 2000).

Turning to leisure activity participation, the ER impact was positive but low. Perhaps this finding would be a consequence of global changes in volunteerism and other forms of leisure activities. Due to the fact that NGOs seem to gradually lose their position and meaning as an exclusive place for social participation through volunteerism, early retirees, and other volunteers only develop weak and unstable relations with their organizations. Hence, volunteers increasingly prefer individual, project-based tasks, they frequently switch organizations and, therefore, they are currently more oriented to a relational type of psychological contract with their NGOs, as recent studies suggest (Aranda et al., 2017).

Finally, the significant influence of ER on retirement satisfaction suggested that some of the concerns about the possible negative effects of ER are exaggerated and partially an artifact of the causes of ER. As Hobfoll's (2011) conservation of resources theory stated, people's well-being is rooted in access to a reserve of valuable resources, which cover basic needs and serve as an expression of worth and status, as well as providing protection against future losses. While work is associated with a broad spectrum of such resources, ER could be associated with others, such as freedom, leisure time, and affects. Furthermore, as recent studies report, not only the influence of available resources near to retirement on satisfaction after the event should be considered but also the influence of distal antecedent correlates on resources (Earl et al., 2015; Topa and Pra, 2017). Despite this fact, retirement can also provoke unease, gloom, and dread, and can be associated with fear of death, a complex emotional phenomenon that includes apprehension both for oneself and for loved ones. Empirical evidence shows that fear of death impinges on most spheres of life, specifically on long-term decisions, but only recent studies begin to consider the role of fear of death in explaining retirement planning (Topa et al., in review).

What methodological and contextual factors would act as potential moderators of the relationship between ER and its antecedent and subsequent correlates?
Extending prior research that started to examine moderators of ER-antecedent links, we meta-analytically compared studies conducted under different welfare regimes, finding that effects of objective financial measures were stronger for social democratic welfare states, whereas subjective finances impact the most on participants from liberal countries. As social democratic welfare states provide access to services based on citizenship, poor physical and mental health both led to ER, showing greater ESs for those countries than for liberal welfare states. As Feldman (2013) warned, these results also seem to confirm the possible interference of third variables in the relations between antecedent correlates and ER. Further analyses would show that differences between professional sectors emerge, revealing still more heterogeneity in the same country. As the Fisher et al. (2016) Model proposed, several social factors indirectly affect subsequent well-being in ER through beliefs about the normative retirement age and negative stereotypes of older employees, which affect the timing of ER and subsequent well-being. Moreover, it should be noted that the financing mechanisms underlying retirement plans differ from one country to the next, as Hershey et al. (2013) suggested, and this should be taken into account when performing group comparisons.

The antecedent correlates-ER relationship was found to vary in terms of the participants' labor status, due to the fact that this implies different task characteristics and working conditions. Our results supported that the ES for the incomeER relationship was stronger for blue- collar workers, and the differences indicated the opposite direction for the subjective income measure, financial security. In the same vein, considering that blue-collar workers perform tasks with higher physical demands, stronger ESs would be expected for the poor physical health-ER relationship, and the results indicate this pattern. Finally, differential job features suggested that the job stress-ER relationship would differ between white- and blue-collar workers. Our results showed higher values for blue-collar workers, although the findings are inconclusive. This may be due, on the one hand, to the existence of a wide range of occupational conditions that have been categorized as white-collar or bluecollar, and diverse factors within these categories could affect the relationships between antecedent or subsequent correlates and ER. Recent studies showed that long-term exposure to low job complexity, i. e.: industrial production work has detrimental effects on cognitive functioning and regional gray matter volume, and it would have an impact on retirement decision making (Oltmanns et al., 2017). As Feldman (2013) stated, workers make appraisals about how unusual it is for someone their age to still be in the workforce, but these evaluations refer to a concrete occupational field.

Moreover, regarding sample comparisons, it should also be considered that people who are far away for retirement would view it as a reaction to their job features. On the contrary, people who are close to retirement "envision retirement primarily in terms of desirability/undesirability of the new role," as BarnesFarrell (2003, p. 173) stated. Hence, any comparison between white-collar and blue-collar workers should consider retirement timing. For instance, other factors could be affected, such as the social presentation of early retirees, in the sense that ER among 
blue-collar workers is socially more accepted than among whitecollar workers (Schreurs et al., 2011). Moreover, these categories can be misleading; as there are highly skilled blue-collar workers (i.e., craftsmen) who tend to have more secure and stable working conditions and suffer from less alienation than routine blue- and white-collar workers (Williamson et al., 1992). So, ER decisions depend on a more complex pattern, and do not respond to this simple categorization into two types of employees.

Our meta-analyses advance the understanding of the impact of voluntariness on ER-antecedent correlates relationships, providing more evidence that the negative income-ER relationship will be stronger for forced early retirees, whereas financial security showed a stronger positive relationship for voluntary retirement. Regarding poor health measures, both physical and mental health proved to have a stronger influence on ER when the decision was voluntary rather than forced.

We also noted that participants' gender moderates the finances-ER relationships, showing a stronger impact both of objective and subjective measures on ER for males than for females. Concomitantly, previous studies suggested reduced financial preparation among women (Taylor and Geldhauser, 2007). Our results provide meta-analytical support to the statements which refer too many reasons-both psychosocial and economical-for gender to have an impact on ER. Men and women lead differentiated social roles that would lead the latter to a discontinuous work trajectory, where factors such as caregiving could affect their decision to retire. In turn, the impact of gender on subsequent retirement decision-making may be mediated by domestic responsibilities, the amount of expected pension at retirement, and the centrality of work in their lives. Moreover, the specific relationship between financial security and ER could be affected by the impact of discontinuous and shorter women's working careers. Perhaps these unclear results support the hypothesis that women tend to deny the information about their future financial hardship in retirement but, in fact, women's pensions will be lower than men's (Topa et al., 2017b).

A substantial body of research exists on the impact of chronological age on ER, and this research consistently shows that age plays a major role in understanding ER. Our results showed that finances, both objective and subjective, showed less impact for those aged below 55 years, whereas poor health measures showed the opposite pattern. These findings are in line with previous research on the relationships between age and a broad range of work-related variables (van der Heijden et al., 2009; Kooij et al., 2010, 2011; Mueller et al., 2013). In this case, mean age would be considered as a proxy variable that masks the existence of various individual perceptions and feelings about whether it is time to retire, along with different normative assumptions of what "early" retirement is.

\section{LIMITATIONS}

As mentioned above, several limitations should be recognized in this study. One of the most relevant sources of difficulty was that, despite the increasing amount of studies on ER, only a limited number of empirical papers test each pair of relationships between variables. Perhaps this is due to that only one or two theoretical frameworks on ER have been offered as a base for primary studies. Moreover, a great amount of empirical evidence has been based on retirees' perceptions as a source of information, without including data from other sources, as supervisors, coworkers, or relatives. This procedure precludes the possibility of distinguishing personal perceptions from more objective ER features.

Secondly, we could only apply the moderator analysis to a limited amount of pairs of variables, due to lack of primary studies in the diverse categories. Although potential moderator factors were examined, it is clear that there are several unknown or not-measurable factors which contribute to ER and about which there are very little data available. As a consequence, our conclusions reached from these analyses have been limited and the moderating effects seemed to be a bit confusing. Again, we strongly recommend future empirical research on ER that deeply analyzes those underexplored relationships.

Despite these limitations, this is a comprehensive review of the most recent literature on the topic and we think that it helps the reader to gain an exhaustive overview of the main antecedent and subsequent correlates as well as of potential moderators of ER.

\section{PRACTICAL IMPLICATIONS}

Taken together, the results of our study show the many causes that characterize the antecedent and subsequent correlates of ER. Given that older workers tend to remain longer in the labor market than in previous decades-which represents a shift from "pro-retirement" to "pro-work" for older workers in the context of retirement (Wang and Shultz, 2010)-, it is a priority to design working conditions and organizational contexts aimed at mitigating the declines in the adjustment between the person and the environment over time for workers in their mid and late career, as negative attitudes toward older workers (Fasbender and Wang, 2017; Beléndez et al., 2018). As recent studies suggested, respect from leaders (Wöhrmann et al., 2017) and organizational climate would have an impact on retirement decision-making (Zacher and Yang, 2016).

One of the more important practical implications is the recommendation to avoid involuntary $\mathrm{ER}$, given the negative effects it has on variables such as health, financial status, and adjustment to retirement. Like other forms of involuntary employment exit, involuntary ER may impact negatively on health through increased stress or the adoption of poor healthrelated behavior (Bartley, 1994), and it can often lead to material deprivation through the reduction of income. However, it can also lead to other forms of deprivation. Employment provides a number of non-economic latent functions (Jahoda, 1982), such as a daily structure and regular activity, a sense of self-efficacy, or identity and social status, which are lost when an individual is forced out of work. Human Resource Management practices designed for older workers (i.e., ER programs, among others) are perceived as a sign that they belong to a devalued social group (Hennekam and Herrbach, 2015; Kmicinska et al., 2016; Derous and Decoster, 2017). As a result, organizations should avoid 
forcing workers who show resistance to ER programs to retire, because the adverse effects on the individuals, their families, and health and social protection systems are disproportionate in comparison with the economic gain of this measure.

These issues, in combination with extrinsic or intrinsic motives, have relevant practical implications in the decisions to prolong working life, for example, through modalities of bridge employment. One study (Dingemans and Henkens, 2014) shows that participation in bridge employment for financial motives was associated with decreases in life satisfaction compared with postretirement-working based on intrinsic motives. In addition, compared with voluntary retirement, involuntary retirement was detrimental to life satisfaction, but participation in a bridge job was found to mitigate this negative shock. As Feldman (2013) argues, declining in the adjustment between older workers and their environment would not, in and of itself, be the only predictor of ER. A subjective comparison with alternative states or roles can be determinant. So, if older workers with poor adjustment to their environment perceive that fit with bridge employment role or full withdrawal role would be even worse, they may not choose to retire voluntarily. In sum, declines in different types of adjustment between older workers and their environment would lead to different ways of work-exit strategies (e.g., ER, retirement at mandatory age, prolonging working life via career or non-career bridge jobs-immediate or delayed, steady or intermittent, self-employed or other employed, same or different employers, as so on; see Beehr and Bennett, 2015). These different exit strategies depend upon the various opportunities open to older workers in their mid and late careers and the context constraints in which they operate (Henry et al., 2017).

One last practical implication is to note that ER is not necessarily the point of no return in working life, but a stage of transition before re-entry into working life at an older age, a trend endorsed by recent data (Cahill et al., 2013). If people accepted ER while still young (for example, before their 60s), going back to work under certain conditions is very feasible and beneficial to the individuals, the organizations, and the social systems and pension systems in countries with a more aged population.

\section{PERSPECTIVES ABOUT EARLY RETIREMENT AND FUTURE RESEARCH}

Although ER was a characteristic of the last two decades of the twentieth century, it is obvious that in the past few years, the tendency has reversed, and a marked preference by older workers and organizations toward maintaining the labor force and prolonging work life is detected. The data indicate that although the labor market participation of older workers is considerably lower than the labor market participation of primeage workers, this gap declined considerably from 1995 until 2014, and the trend toward the ER options, promoted by governments in order to avoid high unemployment rates mainly among young people, has halted and even gone into reverse, as has been observed in Europe and the United States and in other regions of the world (Saba and Guerin, 2005; Cahill et al., 2006; Kantarci and van Soest, 2008; Quinn, 2010). One of the factors that may have contributed to the decline in early labor market withdrawal is the rise of non-standard forms of employment among older workers, which can be linked to the increase of bridge employment modalities (Feldman, 1994; Wang et al., 2008).

In the near future, ER will continue to be a formula used by older workers and organizations to deal with known needs and situations. However, we think that its use will be much more selective and restricted, because the need to cope with population aging, organizations' need to retain highly qualified older workers, maintaining the pension systems, and the promotion of active aging policies and practices will further the use of formulas designed to encourage late careers (e.g., Engelhardt, 2012), post-retirement employment (e.g., Pleau and Shauman, 2013), gradual retirement (e.g., Kantarci and van Soest, 2008), working longer (e.g., Munnell et al., 2008), labor force re-entry (e.g., Cahill et al., 2011), employment of early retirees (Mulders et al., 2014), and bridge employment (Wang et al., 2008). As a consequence, it is plausible to anticipate that knowledge acquired about the antecedent and subsequent correlates of ER will serve to design more efficacious formulas and to optimize their use so they will benefit the people and the organizations, as well as society as a whole. As Fisher et al. (2016) have noted, there are both benefits and drawbacks related to ER, as well as to on-time and later retirement, and there are potential tradeoffs and losses associated with retirement at various time points. The goal of this meta-analytical study was to help identify and better understand these positive and negative factors. We hope to have made this contribution to the literature.

\section{AUTHOR CONTRIBUTIONS}

All authors listed have made a substantial, direct, and intellectual contribution to the work, and approved it for publication.

\section{FUNDING}

This study has received financial support for publication from the institutional program of the UNED Vice Chancellor for Research and Internationalization.

\section{REFERENCES}

*Ahomäki, R., Harila-Saari, A., Matomäki, J., and Lähteenmäki, P. M. (2016). Non-graduation after comprehensive school, and early retirement but not unemployment are prominent in childhood cancer survivorsa Finnish registry-based study. J. Cancer Surviv. 11, 284-294. doi: $10.1007 /$ s11764-016-0574-Z

Alcover, C. M., Crego, A., Guglielmi, D., and Chiesa, R. (2012). Comparison between the Spanish and Italian early work retirement models: a cluster analysis approach. Pers. Rev. 41, 380-403. doi: 10.1108/00483481211212995

Aranda, M., Hurtado, M. D., and Topa, G. (2017). Breach of psychological contract and organizational citizenship behaviors in volunteerism: the mediator role of affect and the moderation of volunteers' age. VOLUNTAS Int. J. Volunt. Nonprofit Organ. doi: 10.1007/s11266-017-9923-4. [Epub ahead of print]. 
Armstrong-Stassen, M., and Schlosser, F. K. (2008). Benefits of a supportive development climate for older workers. J. Manag. Psychol. 23, 419-437. doi: 10.1108/02683940810869033

*Artazcoz, L., Cortès, I., Borrell, C., Escribà-Agüir, V., and Cascant, L. (2010). Gender and social class differences in the association between early retirement and health in Spain. Womens Health Issues 20, 441-447. doi: 10.1016/j.whi.2010.07.007

*Aspnes, A. K. (2008). Self-Regulation Before and After a Developmental Transition: A Study of Adaptive Goal Change in Retirement. Duke University.

*Austrom, M., Perkins, A. J., Damush, T. M., and Hendrie, H. C. (2003). Predictors of life satisfaction in retired physicians and spouses. Social Psychiatry Psychiatr. Epidemiol. 38, 134-141. doi: 10.1007/s00127-003-0610-y

*Bacharach, P., Bamberger, M., Biron, M., and Horowitz-Rozen, M. (2008). Perceived agency in retirement and retiree drinking behavior: job satisfaction as a moderator. J. Voc. Behav. 73, 376-386. doi: 10.1016/j.jvb.2008.07.007

*Bahman, B. (2001). Factors affecting faculty retirement decisions. Soc. Sci. J. 38, 297-305. doi: 10.1016/S0362-3319(01)00114-8

Bal, P. M., Kooij, D. T. A. M., and Rousseau, D. M. (2015). "Introduction to aging workers and the employee-employer relationship," in Aging Workers and the Employee-Employer Relationship, eds P. M. Bal, D. T. A. M. Kooij, and D. M. Rousseau (London: Springer), 1-9.

Barnes-Farrell, J. (2003). "Beyond health and wealth: attitudinal and other influences on retirement decision-making," in Retirement: Reasons, Processes and Results, ed G. Adams and T. Beehr (New York, NY: Springer), 159-187.

Bartley, M. (1994). Unemployment and ill health: understanding the relationship. J. Epidemiol. Community Health 48, 333-337. doi: 10.1136/jech.48.4.333

*Bazzoli, G. (1985). The early retirement decision: the influence of health. J. Human Resour. 20, 214-234. doi: 10.2307/146009

Beehr, T. A. (1986). The process of retirement: a review and recommendations for future investigation. Pers. Psychol. 39, 31-55. doi: 10.1111/j.1744-6570.1986.tb00573.x

Beehr, T. A., and Bennett, M. M. (2015). Working after retirement: features of bridge employment and research directions. Work Aging Retirement 1, 112-128. doi: 10.1093/workar/wau007

Begg, C. B., and Mazumdar, M. (1994). Operating characteristics of a rank correlation test for publication bias. Biometrics 50, 1088-1101. doi: $10.2307 / 2533446$

Beléndez, M., Gómez, A., López, S., and Topa, G. (2018). Psychometric properties of the Spanish version of the Core Self-Evaluations Scale (CSES-SP). Person. Indiv. Diff. 122, 195-197. doi: 10.1016/j.paid.2017.10.034

*Bell, V. V., Blumenthal, S. S., Neumann, N. U., and Schüttler, R. R. (1989). Occupational rehabilitation or early retirement (via social insurance pension) as alternatives for first admission psychiatric patients: results from a 5 year follow-up. Psychopathology 22, 213-217. doi: 10.1159/000 284600

*Bingefors, K., and Isacson, D. (2004). Epidemiology, co-morbidity, and impact on health-related quality of life of self-reported headache and musculoskeletal pain-a gender perspective. Eur. J. Pain 8, 435-450. doi: 10.1016/j.ejpain.2004.01.005

*Blekesaune, M., and Solem, P. (2005). Working conditions and early retirement: a prospective study of retirement behavior. Res. Aging 27, 3-30. doi: $10.1177 / 0164027504271438$

Blöndhal, S., and Scarpetta, S. (1998). The Retirement Decision in OECD Countries, OECD Working Papers No. 202. Paris: OECD Economics Department.

Blundell, R., Meghir, C., and Smith, S. (2002). Pension incentives and the pattern of early retirement. Econ. J. 112, C153-C170. doi: 10.1111/1468-0297.00031

Borenstein, M., Hedges, L., Higgins, J., and Rothstein, H. (2005). Comprehensive Meta-Analysis, Version 2. Englewood, NJ: Biostat.

Borenstein, M., Higgins, J. P., Rothstein, H. R., and Hedges, L. V. (2015). $I^{2}$ Is Not an Absolute Measure of Heterogeneity in a Meta-Analysis. Available online at: https://www.meta-analysis-workshops.com/download/ common-mistakes1.pdf

*Börsch-Supan, A. (2000). Incentive effects of social security on labor force: evidence in Germany and across Europe. J. Public Econ. 78, 25-49. doi: 10.1016/S0047-2727(99)00110-3

*Börsch-Supan, A., and Schuth, M. (2014). "Early retirement, mental health and social networks," in Discoveries in the Economics of Aging, ed D. A. Wise (Chicago, IL: University of Chicago Press), 225-250.
*Böttcher, H. M., Steimann, M., Rotsch, M., Zurborn, K. H., Koch, U., and Bergelt, C. (2013a). Occupational stress and its association with ER and subjective need for occupational rehabilitation in cancer patients. Psychooncology 22, 1807-1814. doi: 10.1002/pon.3224

*Böttcher, H. M., Steimann, M., Ullrich, A., Rotsch, M., Zurborn, K. H., Koch, U., et al. (2013b). Work-related predictors of not returning to work after inpatient rehabilitation in cancer patients. Acta Oncol. 52, 1067-1075. doi: 10.3109/0284186X.2013.792991

*Boumans, N. G., de Jong, A. J., and Vanderlinden, L. (2008). Determinants of early retirement intentions among Belgian nurses. J. Adv. Nurs. 63, 64-74. doi: 10.1111/j.1365-2648.2008.04651.x

*Brockmann, H., Müller, R., and Helmert, U. (2009). Time to retire-time to die? A prospective cohort study of the effects of early retirement on long-term survival. Soc. Sci. Med. 69, 160-164. doi: 10.1016/j.socscimed.2009.04.009

*Bronchetti, E. T. (2007). Work-Related Injuries and Incentives, Adequacy, and Optimality in Workers Compensation. Ph.D. dissertation, Northwestern University. Available from ProQuest Dissertations and Theses database. UMI No.: 3284323.

*Brougham, R. R., and Walsh, D. A. (2009). Early and late retirement exits. Int. J. Aging Hum. Dev. 69, 267-286. doi: 10.2190/AG.69.4.b

*Butterworth, P., Gill, S. C., Rodgers, B., Anstey, K. J., Villamil, E., and Melzer, D. (2006). Retirement and mental health: analysis of the Australian national survey of mental health and well-being. Soc. Sci. Med. 62, 1179-1191. doi: 10.1016/j.socscimed.2005.07.013

*Buxton, J. W., Singleton, N., and Melzer, D. (2005). The mental health of early retirees: national interview survey in Britain. Soc. Psychiatry Psychiatr. Epidemiol. 40, 99-105. doi: 10.1007/s00127-005-0866-5

Cahill, K. E., Giandrea, M. D., and Quinn, J. F. (2006). Retirement patterns from career employment. Gerontologist 46, 514-523. doi: 10.1093/geront/46.4.514

Cahill, K. E., Giandrea, M. D., and Quinn, J. F. (2013). Retirement patterns and the macro economy, 1992-2010: the prevalence and determinants of bridge jobs, phased retirement, and reentry among three recent cohorts of older Americans. Gerontologist 55, 384-403. doi: 10.1093/geront/gnt146

Cahill, K. E., Giandrea, M. D., and Quinn, J. F. (2011). How Does Occupational Status Impact Bridge Job Prevalence? Working Papers (No. 447). US Bureau of Labor Statistics. Available online at: https://www.bls.gov/ore/pdf/ec110050.pdf

*Cardano, M., Costa, G., and Demaria, M. (2004). Social mobility and health in the Turin longitudinal study. Soc. Sci. Med. 58, 1563-1574. doi: 10.1016/S0277-9536(03)00354-X

*Carlsen, K., Dalton, S., Frederiksen, K., Diderichsen, F., and Johansen, C. (2008). Cancer and the risk for taking early retirement pension: a Danish cohort study. Scand. J. Public Health 36, 117-125. doi: 10.1177/1403494807085192

*Carr, E., Hagger-Johnson, G., Head, J., Shelton, N., Stafford, M., Stansfeld, S., et al. (2016). Working conditions as predictors of retirement intentions and exit from paid employment: a 10-year follow-up of the English Longitudinal Study of Ageing. Eur. J. Ageing 13, 39-48. doi: 10.1007/s10433-015-0357-9

*Chang, H., and Yen, S. T. (2011). Full-time, part-time employment and life satisfaction of the elderly. J. Socio Econ. 40, 815-823. doi: 10.1016/j.socec.2011.08.008

Cleveland, J., and Lim, A. (2007). "Employee age and performance in organizations," in Aging and Work in the 21st Century, eds K. S. Shultz and G. A. Adams (Mahwah, NJ: Lawrence Erlbaum), 109-137.

Coe, N. B., and Lindeboom, M. (2008). "Does retirement kill you? Evidence from early retirement windows," in IZA Discussion Papers, No. 3817 (Bonn).

*Cunningham, D. M. (1996). A lifestyle satisfaction study comparing early vs. traditional retirees in a major American industrial organization. Dissert. Abstr. Int. A Hum. Soc. Sci. 56:4460.

*Dal Bianco, C., Trevisan, E., and Weber, G. (2015). "I want to break free.” The role of working conditions on retirement expectations and decisions. Eur. J. Ageing 12, 17-28. doi: 10.1007/s10433-014-0326-8

*Damkjæ, L. H., Deltour, I., Suppli, N. P., Christensen, J., Kroman, N. T., Johansen, C., et al. (2011). Breast cancer and early retirement: associations with disease characteristics, treatment, comorbidity, social position and participation in a six-day rehabilitation course in a register-based study in Denmark. Acta Oncol. 50, 274-281. doi: 10.3109/0284186X.2010.531048

*Damman, M., Henkens, K., and Kalmijn, M. (2011). The impact of midlife educational, work, health, and family experiences on men's early retirement. J. Gerontol. 66, 617-627. doi: 10.1093/geronb/gbr092 
*Damman, M., Henkens, K., and Kalmijn, M. (2015). Women's retirement intentions and behavior: the role of childbearing and marital histories. Eur. J. Population 31, 339-363. doi: 10.1007/s10680-014-9335-8

Davies, E. M. M., Van der Heijden, B. I. J. M., and Flynn, M. (2017). Job satisfaction, retirement attitude and intended retirement age: a conditional process analysis across workers' level of household income. Front. Psychol. 8:891. doi: 10.3389/fpsyg.2017.00891

*Davis, M. A. (2003). Factors related to bridge employment participation among private sector early retirees. J. Voc. Behav. 63, 55-71. doi: 10.1016/S0001-8791(02)00016-7

De Judicibus, M. A., and McCabe, M. P. (2005). Economic deprivation and its effects on subjective wellbeing in families of people with multiple sclerosis. $J$. Mental Health 14, 49-59. doi: 10.1080/09638230500047828

*De Wind, A., Geuskens, G. A., Ybema, J. F., Blatter, B. M., Burdorf, A., Bongers, P. M., et al. (2014). Health, job characteristics, skills, and social and financial factors in relation to early retirement-results from a longitudinal study in the Netherlands. Scand. J. Work Environ. Health 40, 186-194. doi: $10.5271 /$ sjweh.3393

*De Wind, A., and van der Beek, A. J. (2015). The role of ability, motivation, and opportunity to work in the transition from work to early retirement-testing and optimizing the Early Retirement Model. Scand. J. Work Environ. Health 41, 24-35. doi: 10.5271/sjweh.3468

Derous, E., and Decoster, J. (2017). Implicit age cues in resumes: subtle effects on hiring discrimination. Front. Psychol. 8:1321. doi: 10.3389/fpsyg.2017.01321

*Desmarez, P. P., Godin, I. I., and Renneson, B. B. (2007). L' impact des accidents du travail sur le statut socio-économique des victimes. Le Travail Humain, 70, 127-152. doi: 10.3917/th.702.0127

*Desmette, D., and Gaillard, M. (2008). When a 'worker' becomes an 'older worker': the effects of age-related social identity on attitudes towards retirement and work. Career Dev. Int. 13, 168-185. doi: 10.1108/13620430810860567

*Dewa, C. S., Jacobs, P., Thanh, N. X., and Loong, D. (2014). An estimate of the cost of burnout on early retirement and reduction in clinical hours of practicing physicians in Canada. BMC Health Serv. Res. 14:254. doi: 10.1186/1472-6963-14-254

Dingemans, E., and Henkens, K. (2014). Involuntary retirement, bridge employment, and satisfaction with life: a longitudinal investigation. J. Organ. Behav. 35, 575-591. doi: 10.1002/job.1914

Dorfman, L. (2013). "Leisure activities in retirement," in The Oxford Handbook of Retirement, ed M. Wang (New York, NY: Oxford University Press), 339-353.

Duval, S., and Tweedie, R. (2000). Trim and fill: a simple funnel-plot-based method of testing and adjusting for publication bias in meta-analysis. Biometrics 56, 455-463. doi: 10.1111/j.0006-341X.2000.00455.x

Earl, J. K., Gerrans, P., and Halim, V. A. (2015). Active and adjusted: investigating the contribution of leisure, health and psychosocial factors to retirement adjustment. Leisure Sci. 37, 354-372. doi: 10.1080/01490400.2015.1021881

*Eastman, L. (1996). Understanding the Early-Retirement Decision: Beyond Health and Finances. Ph.D. dissertation, University of Georgia. Available from ProQuest Dissertations and Theses database. UMI No.: 9624049.

*Eberhardt, B. (2006). Essays on Retirement Economics. Ph.D. dissertation, The University of Wisconsin - Milwaukee. Available from ProQuest Dissertations and Theses database. UMI No.: 3222396.

Ecklund, E. S. (2014). Core job Dimensions as Predictors of Intended Retirement Timing. Ph. D. dissertation, Indiana University of Pennsylvania. Available from ProQuest Dissertations and Theses database. UMI No.: 3646818.

*Edén, L., Ejlertsson, G., and Petersson, J. (1999). Quality of life among early retirees. Exp. Aging Res. 25, 471-475. doi: 10.1080/036107399243959

Edwards, J. R., Cable, D. M., Williamson, I. O., Lambert, L. S., and Shipp, A. J. (2006). The phenomenology of fit: linking the person and environment to the subjective experience of person-environment fit. J. Appl. Psychol. 91:802. doi: 10.1037/0021-9010.91.4.802

Egger, M., Davey Smith, G., Schneider, M., and Minder, C. (1997). Bias in meta-analysis detected by a simple, graphical test. BMJ 315, 629-634. doi: 10.1136/bmj.315.7109.629

Ekerdt, D. J., and De Viney, S. (1993). Evidence for a preretirement process among older male workers. J. Gerontol. 48, 35-43. doi: 10.1093/geronj/48.2.S35

Ekerdt, D. J., Sparrow, D., Glynn, R. J., and Bosse, R. (1984). Change in blood pressure and total cholesterol with retirement. Am. J. Epidemiol. 120, 64-71. doi: 10.1093/oxfordjournals.aje.a113875
Elder, G. H. Jr., and Johnson, M. K. (2001). "The life course and human development: challenges, lessons, and new directions," in Invitation to the Life Course: Toward New Understandings of Later Life, ed R. A. Settersten (Amityville, NY: Baywood), 3-19.

*Elovainio, M., Forma, P., Kivimäki, M., Sinervo, T., Sutinen, R., and Laine, M. (2005). Job demands and job control as correlates of early retirement thoughts in Finnish social and health care employees. Work Stress 19, 84-92. doi: $10.1080 / 02678370500084623$

*Elovainio, M., Kivimaki, M., Vahtera, J., Ojanlatva, A., Korkeila, K., Suominen, S., et al. (2003). Social support, early retirement, and a retirement preference: a study of 10,489 Finnish adults. J. Occup. Environ. Med. 45, 433-439. doi: 10.1097/01.jom.0000058334.05741.7a

Engelhardt, H. (2012). Late careers in Europe: effects of individual and institutional factors. Eur. Sociol. Rev. 28, 550-563. doi: 10.1093/esr/jcr024

*Enthoven, P., Skargren, E., Carstensen, J., and Oberg, B. (2006). Predictive factors for 1-year and 5-year outcome for disability in a working population of patients with low back pain treated in primary care. Pain 122, 137-144. doi: 10.1016/j.pain.2006.01.022

Esping-Andersen, G. (1999). Social Foundations of Postindustrial Economies. New York, NY: Oxford University Press.

*Euwals, R., Vuuren, D., and Wolthoff, R. (2010). Early retirement Behavior in the Netherlands: evidence from a policy reform. De Economist 158, 209-236. doi: 10.1007/s10645-010-9139-0

Fasbender, U., and Wang, M. (2017). Negative attitudes toward older workers and hiring decisions: testing the moderating role of decision makers' core self-evaluations. Front. Psychol. 7:2057. doi: 10.3389/fpsyg.2016.02057

Feldman, D. (2003). "Endgame: The design and implementation of early retirement incentive programs," in Retirement. Reasons, Processes and Results, ed G. A. Adams and T. A. Beehr (New York, NY: Springer Publishing), 83-114.

Feldman, D. (2013). "Feeling like it's time to retire: a fit perspective on early retirement decisions," in The Oxford Handbook of Retirement, ed M Wang (New York, NY: Oxford University Press), 280-292.

Feldman, D. C. (1994). The decision to retire early: A review and conceptualization. Acad. Manage. Rev. 19, 285-311.

Feldman, D. C., and Beehr, T. A. (2011). A three-phase model of retirement decision making. Am. Psychol. 66, 193-203. doi: 10.1037/a0022153

*Fernández Muñoz, J., Alcover, C. M., and Crego Díaz, A. (2010). Perceptions on the voluntariness in the process of organizational exit in a sample of Spanish early retired. J. Work Organ. Psychol. 26, 135-146.

Fisher, G. G., Chaffee, D. S., and Sonnega, A. (2016). Retirement timing: a review and recommendations for future research. Work Aging Retirement 2, 230-261. doi: 10.1093/workar/waw001

*Friis, K., Ekholm, O., Hundrup, Y., Obel, E., and Grønbæk, M. (2007). Influence of health, lifestyle, working conditions, and sociodemography on early retirement among nurses: the Danish Nurse Cohort Study. Scand. J. Public Health 35, 23-30. doi: 10.1080/14034940600777278

*Frilander, H., Lallukka, T., Viikari-Juntura, E., Heliövaara, M., and Solovieva, S. (2016). Health problems during compulsory military service predict disability retirement: a register-based study on secular trends during 40 years of followup. PLoS ONE 11:e0159786. doi: 10.1371/journal.pone.0159786

Gallo, W. (2013). "The association of retirement with physical and behavioral health," in The Oxford Handbook of Retirement, ed M. Wang (New York, NY: Oxford University Press), 325-338.

*Garcia, M. E. (2011). A Study of Early Childhood Education Teachers' Level of Education, Compensation, Work Environment and Retention. Ph.D. dissertation, Pepperdine University. Available from ProQuest Dissertations and Theses database. UMI No.: 3487434.

*Gowan, M. A. (1998). A preliminary investigation of factors affecting appraisal of the decision to take early retirement. J. Employ. Counsel. 35, 124-137. doi: 10.1002/j.2161-1920.1998.tb00994.x

${ }^{*}$ Graves, R. T. (2006). A Comparative Study of the Life Satisfaction of Early Retirement Military Officers. Doctoral dissertation, Texas A\&M University.

*Green, J. D. (2011). Factors Related to Special Education Teacher Job Commitment: A Study of One Large Metropolitan School District in Southern California. Malibu, CA: Pepperdine University.

${ }^{*}$ Griffin, B., Hesketh, B., and Loh, V. (2012). The influence of subjective life expectancy on retirement transition and planning: a longitudinal study. J. Voc. Behav. 81, 129-137. doi: 10.1016/j.jvb.2012.05.005 
Guglielmi, D., Avanzi, L., Chiesa, R., Mariani, M. G., Bruni, I., and Depolo, M. (2016). Positive aging in demanding workplaces: the gain cycle between job satisfaction and work engagement. Front. Psychol. 7:1224. doi: 10.3389/fpsyg.2016.01224

*Hagger-Johnson, G., Carr, E., Murray, E., Stansfeld, S., Shelton, N., Stafford, M., et al. (2016). Association between midlife health behaviours and transitions out of employment from midlife to early old age: Whitehall II cohort study. BMC Public Health 17:82. doi: 10.1186/s12889-016-3970-4

Hanisch, K. A., and Hulin, C. L. (1991). General attitudes and organizational withdrawal: An evaluation of a causal model. J. Voc. Behav. 39, 110-128. doi: 10.1016/0001-8791(91)90006-8

*Hansez, I. I., Bertrand, F. F., De Keyser, V. V., and Pérée, F. F. (2005). Fin de carrière des enseignants: vers une explication du stress et des retraites prématruées. [Career end for teachers: towards a better understanding of stress and early retirement]. Le Travail Humain 68, 193-223. doi: 10.3917/th.683.0193

*Hardy, M. A., and Hazelrigg, L. (1999). A multilevel model of early retirement decisions among autoworkers in plants with different futures. Res. Aging 21, 275-303. doi: 10.1177/0164027599212006

*Hardy, M. A., and Quadagno, J. (1995). Satisfaction with early retirement: making choices in the auto industry. J. Gerontol. Ser. B Psychol. Sci. Soc. Sci. 50B, S217-S228. doi: 10.1093/geronb/50B.4.S217

*Härkäpää, K. (1992). Psychosocial factors as predictors for early retirement in patients with chronic low back pain. J. Psychosom. Res. 36, 553-559. doi: 10.1016/0022-3999(92)90040-9

*Harkonmäki, K. (2007). Predictors of Disability Retirement: From Early Intentions to Retirement. Ph.D. dissertation, University of Helsinki. Available online at: https://helda.helsinki.fi/bitstream/handle/10138/20313/predicto.pdf? sequence $=2$

*Harkonmäki, K., Korkeila, K., Vahtera, J., Kivimäki, M., Suominen, S., Sillanmäki, L., et al. (2007). Childhood adversities as a predictor of disability retirement. J. Epidemiol. Community Health 61, 479-484. doi: 10.1136/jech.2006.052670

*Harkonmäki, K., Martikainen, P., Lahelma, E., Pitkäniemi, J., Halmeenmäki, T., Silventoinen, K., et al. (2009). Intentions to retire, life dissatisfaction and the subsequent risk of disability retirement. Scand. J. Public Health 37, 252-259. doi: $10.1177 / 1403494808100273$

*Hartig, T., and Fransson, U. (2006). Housing tenure and early retirement for health reasons in Sweden. Scand. J. Public Health 34, 472-479. doi: 10.1080/14034940600554727

*Hayward, M. D. (1986). The influence of occupational characteristics on men's early retirement. Soc. Forces 64, 1032-1045. doi: 10.1093/sf/64.4.1032

Hedges, L. V., and Olkin, I. (1985). Statistical Methods for Meta-Analysis. New York, NY: Academic Press.

*Helvik, A. S., Krokstad, S., and Tambs, K. (2012). Hearing loss and risk of early retirement. The HUNT study. Eur. J. Public Health 23, 617-622. doi: 10.1093/eurpub/cks118

Hemphill, J. F. (2003). Interpreting the magnitudes of correlation coefficients. Am. Psychol. 58, 78-79. doi: 10.1037/0003-066X.58.1.78

Henkens, K. (1999). Retirement intentions and spousal support: a multi-actor approach. J. Gerontol. Soc. Sci. 54B, S63-S73. doi: 10.1093/geronb/54B.2.S63

Henkens, K., and Tazelaar, F. (1994). Early retirement of civil servants in the Netherlands. J. Appl. Soc. Psychol. 24, 1927-1943. doi: 10.1111/j.1559-1816.1994.tb00568.x

*Henkens, K., and Tazelaar, F. (1997). Explaining retirement decisions of civil servants in the Netherlands: intentions, behavior, and the discrepancy between the two. Res. Aging 19, 139-173. doi: 10.1177/0164027597192001

Henkens, K., and van Dalen, H. (2003). "Early Retirement systems and behavior in an international perspective," in Retirement. Reasons, Processes and Results, eds G. A. Adams and T. A. Beehr (New York, NY: Springer Publishing), 242-263.

Hennekam, S., and Herrbach, O. (2015). The influence of age-awareness versus general HRM practices on the retirement decision of older workers. Pers. Rev. 44, 3-21. doi: 10.1108/PR-01-2014-0031

Henry, H., Zacher, H., and Desmette, D. (2017). Future time perspective in the work context: a systematic review of quantitative studies. Front. Psychol. 8:413. doi: 10.3389/fpsyg.2017.00413

*Herrbach, O., Mignonac, K., Vandenberghe, C., and Negrini, A. (2009). Perceived HRM practices, organizational commitment, and voluntary early retirement among late-career managers. Hum. Resour. Manage. 48, 895-915. doi: $10.1002 /$ hrm.20321
Hershey, D. A., Jacobs-Lawson, J. M., and Austin, J. T. (2013). "Effective financial planning for retirement," in The Oxford Handbook of Retirement, ed M. Wang (New York, NY: Oxford University Press), 402-430.

Herzog, A. R., House, J. S., and Morgan, J. N. (1991). Relation of work and retirement to health and well-being in older age. Psychol. Aging 6, 202-211. doi: 10.1037/0882-7974.6.2.202

Hobfoll, S. E. (2011). Conservation of resource caravans and engaged settings. J. Occup. Organ. Psychol. 84, 116-122. doi: 10.1111/j.2044-8325.2010.02016.x

*Horner, E. M. (2014). Subjective well-being and retirement: analysis and policy recommendations. J. Happiness Stud. 15, 125-144. doi: $10.1007 /$ s10902-012-9399-2

Hunter, J. E., and Schmidt, F. L. (1990). Methods of Meta-Analysis. Newbury Park, CA: Sage.

*Husemoen, L. N., Osler, M., Godtfredsen, N. S., and Prescott, E. (2004). Smoking and subsequent risk of early retirement due to permanent disability. Eur. J. Public Health 14, 86-92. doi: 10.1093/eurpub/14.1.86

*Ihle, A., Grotz, C., Adam, S., Oris, M., Fagot, D., Gabriel, R., et al. (2016). The association of timing of retirement with cognitive performance in old age: the role of leisure activities after retirement. Int. Psychogeriatr. 28, 1659-1669. doi: 10.1017/S1041610216000958

*Ilchuk, S. (2009). Retirement Decisions of Women and Men in Response to their Own and Spousal Health. Ph.D. dissertation, Pardee RAND Graduate School. Available online at: http://www.rand.org/pubs/rgs_dissertations/RGSD243. html

*Isaksson, K. (1997). Patterns of Adjustment to Early Retirement. Report from the Department of Psychology, Stockholm Univ. No. 828, 1-13.

Isaksson, K., and Johansson, G. (2000). Adaptation to continued work and early retirement following downsizing: Long-terms effects and gender differences. J. Occup. Organ. Psychol. 73, 241-256. doi: 10.1348/096317900167001

Jahoda, M. (1982). Employment and Unemployment: A Social-Psychological Analysis. New York, NY: Cambridge University Press.

*Janković, J., Erić, M., Stojisavljević, D., Marinković, J., and Janković, S. (2015). Socio-economic differences in cardiovascular health: findings from a cross-sectional study in a middle-income country. PLOS ONE 10:e0141731. doi: 10.1371/journal.pone.0141731

*Jensen, L. D., Bonde, J. P. E., Christensen, M. V., and Maribo, T. (2016). Early retirement among Danish female cleaners and shop assistants according to work environment characteristics and upper extremity complaints: an 11-year follow-up study. BMC Musculoskelet. Disord. 17:202. doi: 10.1186/s12891-016-1053-4

*Johnston, D., and Lee, W. (2009). Retiring to the good life? The short-term effects of retirement on health. Econ. Lett. 103, 8-11. doi: 10.1016/j.econlet.2009.01.015

Kalwij, A., Kapteyn, A., and de Vos, K. (2010). Retirement of older workers and employment of the young. De Economist 158, 341-359. doi: 10.1007/s10645-010-9148-z

Kantarci, T., and van Soest, A. (2008). Gradual retirement: preferences and limitations. De Economist 156, 113-144. doi: 10.1007/s10645-008-9086-1

*Karpansalo, M., Kauhanen, J. J., Lakka, T. A., Manninen, P. P., Kaplan, G. A., and Salonen, J. T. (2005). Depression and early retirement: prospective population based study in middle aged men. J. Epidemiol. Community Health 59, 70-74. doi: 10.1136/jech.2003.010702

*Karpansalo, M., Manninen, P., Kauhanen, J., Lakka, T. A., and Salonen, J. T. (2004). Perceived health as a predictor of early retirement. Scand. J. Work Environ. Health 30, 287-292. doi: 10.5271/sjweh.796

* Keith, P. M. (1985). Work, retirement, and well-being among unmarried men and women. Gerontologist 25, 410-416. doi: 10.1093/geront/25.4.410

*Kerkhofs, M., Lindeboom, M., and Theeuwes, J. (1999). Retirement, financial incentives and health. Labour Econ. 6, 203-227. doi: 10.1016/S0927-5371(99)00016-0

* Kiessling, A., and Henriksson, P. (2005). Perceived cognitive function in coronary artery disease - An unrecognised predictor of unemployment. Qual. Life Res. 14, 1481-1488. doi: 10.1007/s11136-005-0195-x

Kim, J. (2009). Early Retirement and the three types of welfare states. Res. Aging 31, 520-548. doi: 10.1177/0164027509337192

*Kim, J. E., and Moen, P. (2002). Retirement transitions, gender, and psychological well-being: a life-course, ecological model. J. Gerontol. 57B, P212-P222. doi: 10.1093/geronb/57.3.P212 
*Kim, S. (2003). The impact of research productivity on early retirement of university professors. Indus. Relat. J. Econ. Soc. 42, 106-125. doi: 10.1111/1468-232X.00280

Kim, S., and Feldman, D. C. (1998). Healthy, wealthy, or wise: predicting actual acceptance of early retirement incentives at three points of time. Pers. Psychol. 51, 623-642. doi: 10.1111/j.1744-6570.1998.tb00254.x

Kim, S., and Feldman, D. C. (2000). Working in retirement: the antecedents of bridge employment and its consequences for quality of life in retirement. Acad. Manage. J. 43, 1195-1210. doi: 10.2307/1556345

Kmicinska, M., Zaniboni, S., Truxillo, D. M., Fraccaroli, F., and Wang, M. (2016). Effects of rater conscientiousness on evaluations of task and contextual performance of older and younger co-workers. Eur. J. Work Organ. Psychol. 25, 707-721. doi: 10.1080/1359432X.2016.1147428

${ }^{*}$ Knesek, G. E. (1989). Early versus regular retirement: differences in measures of life satisfaction. J. Gerontol. Soc. Work 19, 3-34. doi: 10.1300/J083v19n01_02

Komp, K., van Tilburg, T., and van Groenou, M. B. (2010). Paid work between age 60 and 70 years in Europe: a matter of socio-economic status? Int. J. Aging Later Life 5, 45-75. doi: 10.3384/ijal.1652-8670.105145

Kooij, D. T. A. M., De Lange, A. H., Jansen, P. G. W., Kanfer, R., and Dikkers, J. S. E. (2011). Age and work-related motives: results of a meta-analysis. J. Organ. Behav. 32, 197-225. doi: 10.1002/job.665

Kooij, D. T. A. M., Jansen, P. G. W., Dikkers, J. S. E., and De Lange, A. H. (2010). The influence of age on the associations between HR practices and both affective commitment and job satisfaction: a meta-analysis. J. Organ. Behav. 31, 1111-1136. doi: 10.1002/job.666

*Korkeila, J. J., Oksanen, T. T., Virtanen, M. M., Salo, P. P., Nabi, H. H., Pentti, J. J., et al. (2011). Early retirement from work among employees with a diagnosis of personality disorder compared to anxiety and depressive disorders. Eur. Psychiatry 26, 18-22. doi: 10.1016/j.eurpsy.2009.12.022

Kristof-Brown, A. L., Jansen, K. J., and Colbert, A. E. (2002). A policy-capturing study of the simultaneous effects of fit with jobs, groups, and organizations. J. Appl. Psychol. 87, 985-993. doi: 10.1037/0021-9010.87.5.985

*Kubicek, B., Korunka, C., Hoonakker, P., and Raymo, J. M. (2010). Work and family characteristics as predictors of early retirement in married men and women. Res. Aging 32, 467-498. doi: 10.1177/0164027510364120

*Kuhlman, M. B., Lohse, N., Sørensen, A. M., Larsen, C. F., Christensen, K. B., and Steinmetz, J. (2014). Impact of the severity of trauma on early retirement. Injury 45, 618-623. doi: 10.1016/j.injury.2013.09.007

Kuhn, A., Wuellrich, J.-P., and Zweimüller, J. (2010). Fatal attraction? Access to early Retirement and Mortality. Discussion Paper Series. Forschungsinstitut zur Zukunft der Arbeit, No. 5160. Available online at: https://www.econstor.eu/ bitstream/10419/46065/1/657551368.pdf

*Lahelma, E., Laaksonen, M., Lallukka, T., Martikainen, P., Pietiläinen, O., Saastamoinen, P., et al. (2012). Working conditions as risk factors for disability retirement: a longitudinal register linkage study. BMC Public Health 12:309. doi: $10.1186 / 1471-2458-12-309$

*Laires, P. A., and Gouveia, M. (2014). Association of rheumatic diseases with early exit from paid employment in Portugal. Rheumatol. Int. 34, 491-502. doi: 10.1007/s00296-014-2948-8

*Laires, P. A., Gouveia, M., Canhão, H., and Branco, J. C. (2016). The economic impact of early retirement attributed to rheumatic diseases: results from a nationwide population-based epidemiologic study. Public Health, 140, 151-162. doi: 10.1016/j.puhe.2016.07.004

Lawless, M. (2015). Determinants of Early Withdrawal and of Early Withdrawal by Reason of Disability from the Irish Labour Force in the Third Age. Ph.D. dissertation, University College Dublin, School of Public Health, Physiotherapy and Sports Sciences. Available online at: http://hdl.handle.net/10197/8543

Lawless, M., Buggy, C. J., and Codd, M. B. (2015). Educational influences on early retirement through disability in Ireland. Occup. Med. 65, 303-308. doi: $10.1093 /$ occmed/kqv005

*Leinonen, T., Laaksonen, M., Chandola, T., and Martikainen, P. (2016). Health as a predictor of early retirement before and after introduction of a flexible statutory pension age in Finland. Soc. Sci. Med. 158, 149-157. doi: 10.1016/j.socscimed.2016.04.029

*Lindbohm, M. L., Kuosma, E., Taskila, T., Hietanen, P., Carlsen, K., Gudbergsson, S., et al. (2014). Early retirement and non-employment after breast cancer. Psychooncology 23, 634-641. doi: 10.1002/pon.3459
Litwin, H. L., and Sapir, E. V. (2009). Perceived income adequacy among older adults in 12 countries: findings from the Survey of Health, Ageing, and Retirement in Europe. Gerontologist 49, 397-406. doi: 10.1093/geront/ gnp036

*Lund, T., and Villadsen, E. (2005). Who retires early and why? Determinants of early retirement pension among Danish employees 57-62 years. Eur. J. Ageing 2, 275-280. doi: 10.1007/s10433-005-0013-x

*Markkula, R., Kalso, E., Huunan-Seppälä, A., Koskenvuo, M., Koskenvuo, K., Leino-Arjas, P., et al. (2011). The burden of symptoms predicts early retirement: a twin cohort study on fibromyalgia-associated symptoms. Eur. J. Pain 15, 741-747. doi: 10.1016/j.ejpain.2011.01.004

*Martínez, P. C., Lozano, J., Ancizu, I., Valdés, C. A., and Cándenas, J. (2003). Repercusiones psicológicas y sociales de la prejubilación [Psychological and sociological repercussions of early retirement]. Psicothema 15, 49-53.

*Mein, G. P., Martikainen, H., Hemingway, S., Stansfeld, M., and Marmot, M. (2003). Is retirement good or bad for mental and physical health functioning? Whitehall II longitudinal study of civil servants. Epidemiol. Community Health 57, 46-49. doi: 10.1136/jech.57.1.46

Moher, D., Liberati, A., Tetzlaff, J., Altman, D. G., and PRISMA Group (2010). Preferred reporting items for systematic reviews and meta-analyses: the PRISMA statement. Int. J. Surg. 8, 336-341. doi: 10.1016/j.ijsu.2010.02.007

*Monahan, D. J. (1985). Predictors of Faculty Early Retirement Decision-Making in Arizona. Ph.D. dissertation, The University of Arizona. Available from ProQuest Dissertations and Theses database. UMI No.: 8517502.

*Morois, S., Lemogne, C., Leclerc, A., Limosin, F., Goldberg, S., Goldberg, M., et al. (2015). More than light alcohol consumption predicts early cessation from employment in French middle-aged men. Alcohol Alcohol. 51, 224-231. doi: 10.1093/alcalc/agv092

*Mosca, I., and Barrett, A. (2014). The Impact of Voluntary and Involuntary Retirement on Mental Health: Evidence from Older Irish Adults. IZA Discussion Papers, No. 8723. Available online at: http://hdl.handle.net/10419/ 107515

Mueller, A., De Lange, A., Weigl, M., Oxfart, C., and Van der Heijden, B. (2013). Compensating losses in bridge employment? Examining relations between compensation strategies, health problems, and intention to remain at work. J. Voc. Behav. 83, 68-77. doi: 10.1016/j.jvb.2013.03.002

Mulders, J. A., Henkens, K., and Schippers, J. (2014). Organizations' ways of employing early retirees: the role of age-based HR policies. Gerontologist 55, 374-383. doi: 10.1093/geront/gnt114

Munnell, A. H., Soto, M., and Golub-Sass, A. (2008). Will People Be Healthy Enough to Work Longer? CRR Working Paper No. 2008-11. Available online at: http:// hdl.handle.net/2345/4352

*Myhr, A., Haugan, T., Espnes, G. A., and Lillefjell, M. (2016). Disability pensions among young adults in vocational rehabilitation. J. Occup. Rehabil. 26, 95-102. doi: 10.1007/s10926-015-9590-5

*Negrini, A., Simbula, S., Panari, C., and Alcover, C. M. (2013). The push and pull factors related to early retirees' mental health status: a comparative study between Italy and Spain. J. Work Organ. Psychol. 29, 51-58.

*Neuner, R., Braig, S., Weyermann, M., Kaluscha, R., and Krischak, G. (2013). Short-term goal attainment of in-patient rehabilitation in Germany and longterm risk of early retirement in patients with musculoskeletal diseases: results from a prospective 5-year follow-up study. Disabil. Rehabil. 35, 656-661. doi: $10.3109 / 09638288.2012 .703756$

Newman, D., Jeon, G., and Hulin, C. H. (2013). "Retirement attitudes: considering etiology, measurement, attitude-behavior relationships, and attitudinal ambivalence," in The Oxford Handbook of Retirement, ed M. Wang (New York, NY: Oxford University Press), 228-248.

Nilsson, K., Hydbom, A. R., and Rylander, L. (2016). How are self-rated health and diagnosed disease related to early or deferred retirement? A cross-sectional study of employees aged 55-64. BMC Public Health 16:886. doi: 10.1186/s12889-016-3438-6

OECD (2017). Labour Market Statistics. Labour Force Statistics by Sex and Age: Indicators. Available online at: https://data.oecd.org/emp/labour-forceparticipation-rate.htm (Accessed June 29, 2017).

*Olesen, S., Butterworth, P., and Rodgers, B. (2012). Is poor mental health a risk? Findings from a longitudinal population survey. Soc. Psychiatry Psychiatr. Epidemiol. 47, 735-744. doi: 10.1007/s00127-011-0375-7 
Oltmanns, J., Godde, B., Winneke, A. H., Richter, G., Niemann, C., VoelckerRehage, C., et al. (2017). Don't lose your brain at work - the role of recurrent novelty at work in cognitive and brain aging. Front. Psychol. 8:117. doi: 10.3389/fpsyg.2017.00117

*Osler, M., Mårtensson, S., Prescott, E., and Carlsen, K. (2014). Impact of gender, co-morbidity and social factors on labour market affiliation after first admission for acute coronary syndrome. A cohort study of Danish patients 2001-2009. PLoS ONE 9:e86758. doi: 10.1371/journal.pone.0086758

Owen, J. P., and Belzung, L. D. (1967). Consequences of involuntary ER. A case study of a new labour force phenomenon. Brit. J. Indus. Relat. 5, 162-189. doi: 10.1111/j.1467-8543.1967.tb00506.x

Palaci, F., Jiménez, I., and Topa, G. (2017). Economic cognitions among older adults: parental socialization predicts financial planning for retirement. Front. Aging Neurosci. 9:376. doi: 10.3389/fnagi.2017.00376

*Paradise, M. B., Naismith, S. L., Davenport, T. A., Hickie, I. B., and Glozier, N. S. (2012). The impact of gender on early ill-health retirement in people with heart disease and depression. Aust. N. Z. J. Psychiatry 46, 249-256. doi: $10.1177 / 0004867411427807$

Pattani, S., Constantinovici, N., and Williams, S. (2004). Predictors of reemployment and quality of life in NHS staff one year after early retirement because of ill health: a national prospective study. Occup. Environ. Med. 61, 572-576. doi: 10.1136/oem.2003.011817

Paul, K. I., and Batinic, B. (2010). The need for work: Jahoda's latent functions of employment in a representative sample of the German population. J. Organ. Behav. 31, 45-64. doi: 10.1002/job.622

*Pauwels, V. (2003). Variables Describing the Decision to Retire Before the Age of Sixty-Five. Doctoral dissertation, Texas Tech University.

Perera, S., Sardeshmukh, S. R., and Kulik, C. T. (2014). In or out: job exits of older workers. Asia Pac. J. Hum. Resour. 53, 4-21. doi: 10.1111/1744-7941.12051

*Pfleger, C., Flachs, E., and Koch-Henriksen, N. (2010). Social consequences of multiple sclerosis: clinical and demographic predictors- a historical prospective cohort study. Eur. J. Neurol. 17, 1346-1351. doi: $10.1111 /$ j.1468-1331.2010.03020.x

Piccinelli, M., and Wilkinson, G. (2000). Gender differences in depression. Critical review. Brit. J. Psychiatry 177, 486-492. doi: 10.1192/bjp.177.6.486

Pienta, A. M., and Hayward, M. D. (2002). Who expects to continue working after age 62? The retirement plans of couples. J. Gerontol. Ser. B Psychol. Sci. Soc. Sci. 57, S199-S208. doi: 10.1093/geronb/57.4.S199

*Pit, S. W., Shrestha, R., Schofield, D., and Passey, M. (2010). Health problems and retirement due to ill-health among Australian retirees aged 45-64 years. Health Policy 94, 175-181. doi: 10.1016/j.healthpol.2009.09.003

Pleau, R., and Shauman, K. (2013). Trends and correlates of postretirement employment, 1977-2009. Hum. Relat. 66, 113-141. doi: $10.1177 / 0018726712447003$

*Plouvier, S., Chastang, J. F., Cyr, D., Bonenfant, S., Descatha, A., Goldberg, M., et al. (2015). Occupational biomechanical exposure predicts low back pain in older age among men in the Gazel cohort. Int. Arch. Occup. Environ. Health 88, 501-510. doi: 10.1007/s00420-014-0979-9

Quick, H. E., and Moen, P. (1998). Gender, employment and retirement quality: a life course approach to the differential experiences of men and women. J. Occup. Health Psychol. 3, 44-64. doi: 10.1037/1076-8998.3.1.44

Quinn, J. (2010). Work, retirement, and the encore career: elders and the future of the American workforce. Generations 34, 45-55.

Quintana, D. S. (2015). From pre-registration to publication: a non-technical primer for conducting a meta-analysis to synthesize correlational data. Front. Psychol. 6:1549. doi: 10.3389/fpsyg.2015.01549

*Ranzi, T. L., d'Errico, A., and Costa, G. (2013). Association between chronic morbidity and early retirement in Italy. Int. Arch. Occup. Environ. Health 86, 295-303. doi: 10.1007/s00420-012-0765-5

* Rasmussen, K., and Andersen, J. H. (2005). Individual factors and GP approach as predictors for the outcome of rehabilitation among long-term sick listed cases. J. Occup. Rehabil. 15, 227-235. doi: 10.1007/s10926-005-1221-0

Raymo, J. M., Warren, J. R., Sweeney, M. M., Hauser, R. M., and Ho, J. H. (2011). Precarious employment, bad jobs, labor unions, and early retirement. J. Gerontol. Ser. B Psychol. Sci. Soc. Sci. 66, 249-259. doi: 10.1093/geronb/gbq106

*Rennemark, M., and Berggren, T. (2006). Relationships between work-status and leisure lifestyle at the age of 60 years old. Eur. J. Ageing, 3, 82-88. doi: $10.1007 /$ s10433-006-0029-x
*Robbins, S. B., Lee, R. M., and Wan, T. H. (1994). Goal continuity as a mediator of early retirement adjustment: testing a multidimensional model. J. Counsel. Psychol. 41, 18-26. doi: 10.1037/0022-0167.41.1.18

Roberts, J., Rice, N., and Jones, A. (2010). Early retirement among men in Britain and Germany: how important is health? Geneva Pap. Risk Insur. Issues Pract. 35, 644-667. doi: 10.1057/gpp.2010.24

Robertson, A. (2000). 'I saw the handwriting on the wall': shades of meaning in reasons for early retirement. J. Aging Stud. 14, 63-79. doi: 10.1016/S0890-4065(00)80016-X

Robroek, S. J. W., Reeuwijk, K. G., Hillier, F. C., Bambra, C. L., van Rijn, R. M., and Burdorf, A. (2013). The contribution of overweight, obesity, and lack of physical activity to exit from paid employment: a meta-analysis. Scand. J. Work Environ. Health 39, 233-240. doi: 10.5271/sjweh.3354

*Robroek, S. J., Rongen, A., Arts, C. H., Otten, F. W., Burdorf, A., and Schuring, M. (2015). Educational inequalities in exit from paid employment among Dutch workers: the influence of health, lifestyle and work. PLoS ONE 10:e0134867. doi: 10.1371/journal.pone.0134867

*Rojanawon, W. (2001). Income and Wealth Differentials of Late MiddleAged United States-Born and Foreign-Born Households in the United States: Implications for Immigrant Social Security and Retirement Income. Ph.D. dissertation, Boston College. Available from ProQuest Dissertations and Theses database. UMI No.: 3038925.

Rosenkoetter, M., Garris, J., and Engdahl, R. (2001). Postretirement use of time: implications for retirement planning and postretirement management. Act. Adapt. Aging 25, 1-17. doi: 10.1300/J016v25n03_01

Rosenthal, R. (1979). The "file drawer problem" and tolerance for null results. Psychol. Bull. 86, 638-641.

*Saba, T., and Guerin, G. (2005). Extending employment beyond retirement age: the case of health care managers in Quebec. Public Pers. Manag. 34, 195-214. doi: $10.1177 / 009102600503400205$

*Sargent-Cox, K., Butterworth, P., and Anstey, K. (2011). The global financial crisis and psychological health in a sample of Australian older adults: a longitudinal study. Soc. Sci. Med. 73, 1105-1112. doi: 10.1016/j.socscimed.2011.06.063

*Savwoir, A. J. (1986). Conditions Associated with Early Retirement Decisions. Doctoral dissertation, Teachers College, Columbia University.

Schalk, R., and Desmette, D. (2015). "Intentions to continue working and its predictors," in Aging Workers and the Employee-Employer Relationship, eds P. M. Bal, D. T. A. M. Kooij, and D. M. Rousseau (London: Springer), 187-201.

*Schils, T. (2008). ER in Germany, the Netherlands and the United Kingdom: a longitudinal analysis of individual factors and institutional regimes. Eur. Sociol. Rev. 24, 315-329. doi: 10.1093/esr/jcn009

*Schnabel, R., Friedel, H., Erfurth, A., Angermayer, M., Clouth, J., and Eichmann, F. (2008). Predisposing factors for early retirement in patients with schizophrenia in Germany. Eur. J. Health Econ. 9, 265-274. doi: 10.1007/s10198-007-0074-1

*Schneider, B., Grebner, K., Schnabel, A., Hampel, H., Georgi, K., and Seidler, A. (2011). Impact of employment status and work-related factors on risk of completed suicide: a case-control psychological autopsy study. Psychiatry Res. 190, 265-270. doi: 10.1016/j.psychres.2011.07.037

* Schofield, D. J., Callander, E. J., Shrestha, R. N., Percival, R., Kelly, S. J., and Passey, M. E. (2013). Premature retirement due to ill health and income poverty: a cross-sectional study of older workers. BMJ Open 3:e002683. doi: 10.1136/bmjopen-2013-002683

*Schofield, D. J., Shrestha, R. N., Percival, R., Kelly, S. J., Passey, M. E., and Callander, E. J. (2011). Quantifying the effect of early retirement on the wealth of individuals with depression or other mental illness. Brit. J. Psychiatry 198, 123-128. doi: 10.1192/bjp.bp.110.081679

Schreurs, B., van Emmerik, H. V., De Cuyper, N., Notelaers, G., and De Witte, H. (2011). Job demands-resources and early retirement intention: differences between blue- and white-collar workers. Econ. Indus. Democracy 32, 47-68. doi: $10.1177 / 0143831$ X10365931

*Schuring, M., Burdorf, L., Kunst, A., and Mackenbach, J. (2007). The effects of ill health on entering and maintaining paid employment: evidence in European countries. J. Epidemiol. Community Health 61, 597-604. doi: $10.1136 /$ jech.2006.047456

*Segel-Karpas, D., Bamberger, P. A., and Bacharach, S. B. (2013). Income decline and retiree well-being: the moderating role of attachment. Psychol. Aging 28, 1098-1107. doi: $10.1037 / \mathrm{a} 0034672$ 
Segura, A., García-Orozco, J., and Topa, G. (2017). "Healthy organizations promote employee well-being: the moderating role of selection, optimization and compensation strategies," in Paper Presented at the EAWOP Small Group Meeting "Fostering Healthy Organizations: A Cross-Cultural Perspective" (Florence).

*Seitsamo, J. (2005). Qualities of work, functioning and early retirement. A longitudinal study among Finnish ageing workers in 1981-1997. Int. Congress Ser. 1280, 136-141. doi: 10.1016/j.ics.2005.02.045

Sejbaek, C. S., Nexo, M. A., and Borg, V. (2012). Work-related factors and early retirement intention: a study of the Danish eldercare sector. Eur. J. Public Health 23, 611-616. doi: 10.1093/eurpub/cks117

*Sharma, A. A., Sharp, D. M., Walker, L. G., and Monson, J. T. (2008). Stress and burnout in colorectal and vascular surgical consultants working in the UK National Health Service. Psychooncology 17, 570-576. doi: 10.1002/pon.1269

*Shim, M. J., and Amick, B. (2010). "The association between self-reported health and type of retirement," in Poster session presented at The Population Association Annual Meeting (Texas).

*Shultz, K. S., Morton, K. R., and Weckerle, J. R. (1998). The influence of push and pull factors on voluntary and involuntary early retirees' retirement decision and adjustment. J. Voc. Behav. 53, 45-57. doi: 10.1006/jvbe.1997.1610

Siegrist, J., Wahrendorf, M., von dem Knesebeck, O., Jürges, H., and Börsch-Supan, A. (2006). Quality of work, well-being, and intended early retirement of older employees-baseline results from the SHARE Study. Eur. J. Public Health 17, 62-68. doi: 10.1093/eurpub/ckl084

*Simbula, S., Negrini, A., Crego, A., Martínez-Iñigo, D., and Depolo, M. (2004). "La Retraite Volontaire en Italie et la Préretraite Forcée en Espagne: une Étude Internationale pour mesurer les Ressources et les Effets sur le Bien-Être Individue," in La Qualité de la Vie au Travail Dans les Années 2000, ed A. Battisteli, M. Depolo, and F. Fraccaroli (Bologna: Clueb), 828-836.

*Singer, S., Meyer, A., Wienholz, S., Briest, S., Brown, A., Dietz, A., et al. (2014). Early retirement in cancer patients with or without comorbid mental health conditions: a prospective cohort study. Cancer 120, 2199-2206. doi: $10.1002 / \mathrm{cncr} .28716$

*Smith, B. C., Holtom, T. R., and Mitchell, T. (2011). Enhancing precision in the prediction of voluntary turnover and retirement. J. Voc. Behav. 79, 290-302. doi: 10.1016/j.jvb.2010.11.003

Sterne, J. A., Becker, B. J., and Egger, M. (2005). “The funnel plot," in Publication Bias in Meta-Analysis: Prevention, Assessment and Adjustments, eds $\mathrm{H}$. Rothstein, A. Sutton, and M. Borenstein (Chichester: John Wiley \& Sons, Ltd.), 75-98.

* Suh, J. (2000). Social Security, Work Incentives, and Retirement Behavior of Older Men. Ph.D. dissertation, The University of Alabama. Available from ProQuest Dissertations and Theses database. UMI No.: 9996500.

*Swan, G., Dame, A., and Carmelli, D. (1991). Involuntary retirement, Type A behavior, and current functioning in elderly men: 27-year follow-up of the Western Collaborative Group Study. Psychol. Aging 6, 384-391. doi: 10.1037/0882-7974.6.3.384

Szinovacz, M. (2003). "Contexts and pathways: retirement as an institution, process and experience," in Retirement: Reasons, Processes and Results, eds G. Adams and T. Beehr (New York, NY: Springer), 6-52.

Szinovacz, M. (2013). "A multilevel perspective for retirement research," in The Oxford Handbook of Retirement, ed M. Wang (New York, NY: Oxford University Press), 152-176.

*Szinovacz, M. E., and Davey, A. (2004). Retirement transitions and spouse disability: effects on depressive symptoms. J. Gerontol. Ser. B Psychol. Sci. Soc. Sci. 59B, S333-S342. doi: 10.1093/geronb/59.6.S333

* Szubert, Z., and Sobala, W. (2005). Current determinants of early retirement among blue collar workers in Poland. Int. J. Occup. Med. Environ. Health 18, $177-184$.

Talaga, J., and Beehr, T. A. (1989). "Retirement: a psychological perspective," in International Review of Industrial and Organizational Psychology, eds C. L. Cooper and I. T. Robertson (Oxford: John Wiley), 185-211.

*Taskila-Åbrandt, T., Pukkala, E., Martikainen, R., Karjalainen, A., and Hietanen, P. (2005). Employment status of Finnish cancer patients in 1997. Psychooncology 14, 221-226. doi: 10.1002/pon.838

Taylor, A. W., Pilkington, R., Feist, H., Dal Grande, E., and Hugo, G. (2014). A survey of retirement intentions of baby boomers: an overview of health, social and economic determinants. BMC Public Health 14:355. doi: 10.1186/1471-2458-14-355

Taylor, M. A., and Shore, L. M. (1995). Predictors of planned retirement age: an application of Beehr's model. Psychol. Aging 10, 76-83. doi: $10.1037 / 0882-7974.10 .1 .76$

Taylor, M., and Geldhauser, H. (2007). "Low income older workers," in Aging and work in the 21st Century, eds K. Shultz and G. Adams (Mahwah, NJ: Erlbaum), 25-51.

*Taylor, M., Goldberg, C., Shore, L. M., and Lipka, P. (2008). The effects of retirement expectations and social support on post-retirement adjustment: a longitudinal analysis. J. Manag. Psychol. 23, 458-470. doi: 10.1108/02683940810869051

*Thorsen, S. V., Jensen, P. H., and Bjørner, J. B. (2016). Psychosocial work environment and retirement age: a prospective study of 1876 senior employees. Int. Arch. Occup. Environ. Health 89, 891-900. doi: 10.1007/s00420-0161125-7

*Tian, H. (2007). Caring for Depression and Comorbid Pain: Evidence from HRS and HCC. Ph.D. dissertation, Pardee RAND Graduate School.

Topa, G., Guglielmi, D., and Depolo, M. (2016). Effort-reward imbalance and organisational injustice among aged nurses: a moderated mediation model. J. Nurs. Manag. 24, 834-842. doi: 10.1111/jonm. 12394

Topa, G., and Herrador-Alcaide, T. (2016). Procrastination and financial planning for retirement: a moderated mediation analysis. J. Neurosc. Psychol. Econ. 9, 169-181. doi: 10.1037/npe0000065

Topa, G., Jiménez, I., Valero, E., and Ovejero, A. (2017a). Resource loss and gain, life satisfaction, and health among retirees in Spain: mediation of social support. J. Aging Health 29, 415-436. doi: 10.1177/08982643166 35589

Topa, G., Moriano, J. A., Depolo, M., Alcover, C., and Morales, J. (2009). Antecedents and consequences of retirement planning and decision-making: a meta-analysis and model. J. Voc. Behav. 75, 38-55. doi: 10.1016/j.jvb.2009.03.002

Topa, G., Moriano, J., Depolo, M., Alcover, C. M., and Moreno, A. (2011). Retirement and wealth relationships: meta-analysis and SEM. Res. Aging 33, 501-528. doi: 10.1177/0164027511410549

Topa, G., and Pra, I. (2017). Retirement adjustment quality: optimism and self-efficacy as antecedents of resource accumulation. Appl. Res. Qual. Life doi: 10.1007/s11482-017-9571-2. [Epub ahead of print].

Topa, G., Segura, A., and Pérez, S. (2017b). Gender differences in retirement planning: a longitudinal study among Spanish Registered Nurses. J. Nurs. Manag. doi: 10.1111/jonm.12586

Topa, G., and Valero, E. (2017). Preparing for retirement: how self-efficacy and resource threats contribute to retirees' satisfaction, depression, and losses. Eur. J. Work Organ. Psychol. 26, 811-827. doi: 10.1080/1359432X.2017. 1375910

Truxillo, D. M., and Fraccaroli, F. (2013). Research themes on age and work: introduction to the Special Issue. Eur. J. Work Organ. Psychol. 22, 249-252. doi: 10.1080/1359432X.2013.786604

*Tsai, S. P., Wendt, J. K., Donnelly, R. P., de Jong, G., and Ahmed, F. S. (2005). Age at retirement and long term survival of an industrial population: prospective cohort study. BMJ: Brit. Med. J. 331, 995-999. doi: 10.1136/bmj.38586.448704.E0

*Tunceli, K. (2003). A Structural Model of the Effect of Retiree Health Insurance on Early Retirement. Ph.D. dissertation, The Pennsylvania State University. Available from ProQuest Dissertations and Theses database. UMI No.: 3106337.

*Tuohy, A., Knussen, C., and Wrennall, M. J. (2005). Effects of age on symptoms of anxiety and depression in a sample of retired police officers. Psychol. Aging 20, 202-210. doi: 10.1037/0882-7974.20.2.202

*Uggerby, P., Nielsen, R., Correll, C. U., and Nielsen, J. (2011). Characteristics and predictors of long-term institutionalization in patients with schizophrenia. Schizophrenia Res. 131, 120-126. doi: 10.1016/j.schres.2011. 03.001

Vaillant, G. E. (2002). Aging Well. Boston, MA: Little, Brown and Co.

*Vaillant, G. E., Di Rago, A. C., and Mukamal, K. (2006). Natural history of male psychological health, XV: retirement satisfaction. Am. J. Psychiatry 163, 682-688. doi: 10.1176/ajp.2006.163.4.682 
van Dam, K., van der Vorst, J. D. M., and van der Heijden, B. I. J. M. (2009). Employees' intentions to retire early: a case of planned behavior and anticipated work conditions. J. Career Dev. 35, 265-289. doi: 10.1177/08948453083 27274

van Dam, K., van der Vorst, J. D. M., and van der Heijden, B. I. J. M. (2010). Le intenzioni di pensionamento anticipato dei dipendenti. GIPO Giornale Italiano Di Psicologia Dell' Orientamento, 11, 33-46.

van den Berg, T. I., Elders, L. A., and Burdorf, A. (2010). Influence of health and work on early retirement. J. Occup. Environ. Med. 52, 576-583. doi: 10.1097/JOM.0b013e3181de8133

van der Heijden, B. I. J. M., de Lange, A. H., Demerouti, E., and van der Heijde, C. M. (2009). Age effects on the employability-career success relationship. J. Voc. Behav. 74, 156-164. doi: 10.1016/j.jvb.2008.12.009

*Van Droogenbroeck, F., and Spruyt, B. (2014). To stop or not to stop: an empirical assessment of the determinants of early retirement among active and retired senior teachers. Res. Aging 36, 753-777. doi: 10.1177/01640275135 19449

van Rijn, R. M., Robroek, S. J., Brouwer, S., and Burdorf, A. (2014). Influence of poor health on exit from paid employment: a systematic review. Occup. Environ. Med. 71, 295-301. doi: 10.1136/oemed-2013-101591

*van Solinge, H. (2006). Changing Tracks: Studies on Life after ER in the Netherlands. Ph.D. dissertation, Utrecht University. Available online at: http:// dspace.library.uu.nl/handle/1874/13350

van Solinge, H. (2007). Health change in retirement: a longitudinal study among older workers in the Nederland. Res. Aging 29, 225-256. doi: $10.1177 / 0164027506298223$

van Solinge, H. (2013). “Adjustment to retirement," in The Oxford Handbook of Retirement, ed M. Wang (New York, NY: Oxford University Press), 311-324.

van Solinge, H., and Henkens, K. (2007). Involuntary retirement: the role of restrictive circumstances, timing, and social embeddedness. J. Gerontol. Soc. Sci. 62B, S295-S303. doi: 10.1093/geronb/62.5.S295

Vogel, R. M., and Feldman, D. C. (2009). Integrating the levels of personenvironment fit: the roles of vocational fit and group fit. J. Voc. Behav. 75, 68-81. doi: 10.1016/j.jvb.2009.03.007

*von Bonsdorff, M. E., Huuhtanen, P., Tuomi, K., and Seitsamo, J. (2010a). Predictors of employees' Early Retirement intentions: an 11-year longitudinal study. Occup. Med. 60, 94-100.

von Bonsdorff, M. E., Vanhala, S., Seitsamo, J., Janhonen, M., and Husman, P. (2010b). Employee well-being, early-retirement intentions, and company performance. J. Occup. Environ. Med. 52, 1255-1261. doi: 10.1097/JOM.0b013e3181f9f0b9

Von Nordheim, F. (2004). Responding well to the challenge of an ageing and shrinking workforce. European Union policies in support of member state efforts to retain reinforce and re-integrate older workers in employment. Soc. Policy Soc. 3, 145-153. doi: 10.1017/S1474746403001672

Wang, M. (2007). Profiling retirees in the retirement transition and adjustment process. Examining the longitudinal change patterns of retirees' psychological well-being. J. Appl. Psychol. 92, 455-474. doi: 10.1037/0021-9010.92.2.455

Wang, M. (2013). "Retirement research: concluding observations and strategies to move forward," in The Oxford Handbook of Retirement, ed M. Wang (New York, NY: Oxford University Press), 603-615.
Wang, M., and Shultz, K. S. (2010). Employee retirement: a review and recommendations for future investigation. J. Manage. 36, 172-206. doi: 10.1177/0149206309347957

Wang, M., Zhan, Y., Liu, S., and Shultz, K. S. (2008). Antecedents of bridge employment: a longitudinal investigation. J. Appl. Psychol. 93, 818-830. doi: 10.1037/0021-9010.93.4.818

Warren, A. M. (2009). An Investigation of Mandatory Retirement: A Qualitative and Quantitative Examination. Ph.D. dissertation, Saint Mary's University, Halifax, Nova Scotia. Available from ProQuest Dissertations and Theses databases.

*Wedegaertner, F., Arnhold-Kerri, S., Sittaro, N. A., Bleich, S., Geyer, S., and Lee, W. E. (2013). Depression-and anxiety-related sick leave and the risk of permanent disability and mortality in the working population in Germany: a cohort study. BMC Public Health 13:145. doi: 10.1186/1471-2458-13-145

*Westerlund, H., Kivimäki, M., Singh-Manoux, A., Melchior, M., Ferrie, J., Pentti, J., et al. (2009). Self-rated health before and after retirement in France (GAZEL): a cohort study. Lancet 374, 1889-1896. doi: 10.1016/S0140-6736(09)61570-1

*Whipple, J. (2001). Early-Retirement Decision of Baby Boomer Scientists and Engineers. Ph.D. dissertation, The Claremont Graduate University. Available from ProQuest Dissertations and Theses database. UMI No.: 3015970.

*Whitney, R. L., Bell, J. F., Reed, S. C., Lash, R., Bold, R. J., Kim, K. K., et al. (2016). Predictors of financial difficulties and work modifications among cancer survivors in the United States. J. Cancer Surviv. 10, 241-250. doi: 10.1007/s11764-015-0470-y

Williamson, R. C., Rinehart, A. D., and Blank, T. O. (1992). Early Retirement: Promises and Pitfalls. New York, NY: Springer.

Wöhrmann, A., Fasbender, U., and Deller, J. (2017). Does more respect from leaders postpone the desire to retire? Understanding the mechanisms of retirement decision-making. Front. Psychol. 8:1400. doi: 10.3389/fpsyg.2017.01400

*Wuebbeke, C. (2011). The limitations of activation policies: unemployment at the end of working life. Ageing Soc. 31, 977-1002. doi: $10.1017 /$ S0144686X10000929

Yeung, D., and Zhou, X. (2017). Planning for retirement: longitudinal effect on retirement resources and post-retirement well-being. Front. Psychol. 8:1300. doi: 10.3389/fpsyg.2017.01300

Zacher, H., and Yang, J. (2016). Organizational climate for successful aging. Front. Psychol. 7:1007. doi: 10.3389/fpsyg.2016.01007

Zappalà, S., Depolo, M., Fraccaroli, F., Guglielmi, D., and Sarchielli, G. (2008). Postponing job retirement? Psychosocial influences on the preference for early or late retirement. Career Dev. Int. 13, 150-167. doi: 10.1108/13620430810860558

Conflict of Interest Statement: The authors declare that the research was conducted in the absence of any commercial or financial relationships that could be construed as a potential conflict of interest.

Copyright (c) 2018 Topa, Depolo and Alcover. This is an open-access article distributed under the terms of the Creative Commons Attribution License (CC BY). The use, distribution or reproduction in other forums is permitted, provided the original author(s) or licensor are credited and that the original publication in this journal is cited, in accordance with accepted academic practice. No use, distribution or reproduction is permitted which does not comply with these terms.

*Studies included in the meta-analyses are marked with an asterisk. 